\title{
Uso de espectrometria de raios-gama aplicado à caracterização de sucessões argilosas: estudo de caso em um intervalo devoniano da borda leste da Bacia do Paraná, Brasil
}

\author{
Josiane B. PLANTZ', Thiago G. CARELLI², Bruno R. de C. SANTOS', \\ Paula MENDLOWICZ-MAULLER ${ }^{1}$, Leonardo BORGHI' \& Renato R. C. RAMOS ${ }^{3}$

\begin{abstract}
' Laboratório de Geologia Sedimentar, Instituto de Geociências, Departamento de Geologia, Universidade Federal do Rio de Janeiro. Av. Athos da Silveira Ramos, 274, CEP 21.941-916, Campus Ilha do Fundão, Rio de Janeiro, RJ, Brasil (josianeplantz@gmail.com.br, bruno.rafael@gmx.com, mendlowicz@gmail.com, lborghi@geologia.ufrj.br).
\end{abstract} \\ ${ }^{2}$ Instituto de Biociências, Departamento de Ciências Naturais, Universidade Federal do Estado do Rio de \\ Janeiro. Av. Pasteur, 458, CEP 22.290-240, Urca, Rio de Janeiro, RJ, Brasil (tgcarelli@gmail.com). \\ ${ }^{3}$ Departamento de Geologia e Paleontologia, Museu Nacional da Universidade Federal do Rio de Janeiro. \\ Quinta da Boa Vista, s/n, CEP 20.940-040, São Cristóvão, Rio de Janeiro, RJ, Brasil (rramos@mn.ufrj.br).
}

\begin{abstract}
Resumo. Dados diretos de subsuperfície são ainda escassos na borda leste da Bacia do Paraná e perfis de poços são rotineiramente utilizados para interpretação litológica. Com base nisto, propõe-se um estudo integrado que objetiva a caracterização litológica e gamaespectométrica do testemunho do poço 2-TB-1-PR (Tibagi), amostrado continuamente da superfície $(0,00 \mathrm{~m})$ até 451,60 m de profundidade, além de reconhecer, em subsuperfície, as unidades siluro-devonianas que afloram na área de estudo. As características litológicas permitiram distinguir cinco intervalos (A-E), no Intervalo A (438,80-451,60 m) observa-se arenitos com estratificação cruzada atribuídos à Formação Furnas; o Intervalo B (432,60-438,80 m) é constituído por arenitos laminados intercalados com argilitos, que apresentam elevadas médias de Th, K e GR e é correlato as "camadas de transição" presentes entre as formações Furnas e Ponta Grossa. Nos intervalos C (208,10-432,60 m) e D (13,00-208,10 m) predominam argilitos laminados típicos da Formação Ponta Grossa, com idades entre o Neopraguiano e o Eo/MesoGivetiano(?). Intercalações entre argilitos e arenitos estão presentes, bem como arenitos, que, por vezes, exibem laminações cruzadas por onda. No intervalo $D$ as camadas de arenito ocorrem com maior frequência e espessura e no $\mathrm{C}$ as rochas apresentam médias de Th, $\mathrm{U}, \mathrm{K}$ e GR inferiores às do testemunho. O Intervalo $E(13,00-0,00 \mathrm{~m})$, constituído por rochas mosqueadas e com valores elevados de Th, U e K é correlato ao Grupo Itararé (Permo-carbonífero). A pequena dispersão dos valores de Th, U, K e GR não permitiu a elaboração de um modelo de predição litológica para sucessões argilosas, mas salienta a existência de padrões atribuídos ao paleoambiente deposicional.
\end{abstract}

Palavras-chave. Caracterização litológica, Espectrometria de raio-gama, Sucessões argilosas, Testemunho de sondagem.

\begin{abstract}
GAMMA-RAY SPECTROMETRY APPLIED TO MUDDY SUCCESSIONS CHARACTERIZATION: STUdY CASE IN A DEVONIAN INTERVAL FROM EAST BORDER of PARANÁ BASIN, BRAZIL. Direct subsurface data are still scarce on the eastern border of the Paraná Basin and well-logs are routinely used for lithological interpretation. Based on this, proposes an integrated study that aims the lithological and gamma-spectrometric characterization of the drill core 2-TB-1-PR (Tibagi), continuously sampled from the surface $(0.00 \mathrm{~m})$ up to $451.60 \mathrm{~m}$ deep, and the subsurface recognition of the siluro-devonian units that outcrop on the study area. The lithological characteristics described allowed to distinguish five intervals (A-E), in the Interval A (438.80$451.60 \mathrm{~m}$ ) there are cross-stratified sandstones attributed to the Furnas Formation; the Interval B (432.60-438.80 m) consists of laminated sandstones interleaved with claystones, which have high averages of Th, $\mathrm{K}$ and GR and are correlated to the "transition layers" between Furnas and Ponta Grossa formations. In the C (208.10-432.60 m) and D (13.00-208.10 m) intervals there is a predominance of laminated claystones, typical of Ponta Grossa Formation, with ages between Late Praguian to Early/Middle Givetian(?). Intercalations between claystone and sandstone are present, as well as sandstones, that may exhibit wavy cross-lamination. The higher frequency and thickness of sandstones at Interval D differ it from $\mathrm{C}$ and rocks of Interval $\mathrm{C}$ show Th, $\mathrm{U}, \mathrm{K}$ and GR averages lower than those calculated for the drill core. Interval E (13.00-0.00 m) consisting
\end{abstract}


of mottled rocks with high values of Th, $\mathrm{U}$ and $\mathrm{K}$, it is correlates with Itararé Group (Permocarboniferous). The small dispersion of the Th, $\mathrm{U}, \mathrm{K}$ and $\mathrm{GR}$ values did not allow the elaboration of a lithological prediction model for muddy successions, but it highlights patterns attributed to the depositional paleoenvironment.

Keywords. Lithological characterization, Gamma-ray spectrometry, Muddy successions, Drill core.

\section{Introdução}

A borda leste da Bacia do Paraná foi quase que integralmente reafeiçoada após o soerguimento flexural do Arco de Ponta Grossa. A atuação de processos erosivos promoveu a remoção de uma seção sedimentar da ordem de 2.500 m (Zanotto, 1993), sendo responsável pela exposição de rochas mais antigas do substrato, dentre elas as siluro-devonianas da Supersequência Paraná (Milani et al., 2007).

Diversos pesquisadores, dentre os principais, Petri (1948); Lange \& Petri (1967); Assine (1996); Milani et al. (2007) e Grahn et al. (2013), propuseram divisões, em unidades litoestratigráficas formais, para as rochas siluro-devonianas da Bacia do Paraná. Salvo peculiaridades, admite-se a ocorrência de um pacote arenoso inferior, a Formação Furnas, e outro, essencialmente pelítico, a Formação Ponta Grossa.

Tais unidades ocorrem em uma estreita faixa de afloramentos ao longo de ferrovias e estradas que atravessam a região do Arco de Ponta Grossa e, mesmo hoje, após um vasto conhecimento acumulado, alguns questionamentos, como por exemplo: a natureza do paleoambiente deposicional (continental, parálico ou marinho) da Formação Furnas, o tipo de contato entre as formações Furnas e Ponta Grossa e a subdivisão em membros da Formação Ponta Grossa, são comuns na literatura. Estes questionamentos estão associados ao baixo grau de preservação dos afloramentos (obliterados por processos intempéricos) e à falta de exposições contínuas e representativas, principalmente dos pelitos da Formação Ponta Grossa.

A região carece de testemunhagens profundas e contínuas, contando apenas com amostras de calha e perfis de poços, dentre os quais o de raio-gama, comumente usado para predição litológica, mas que, apesar do uso consagrado, apresenta diversas ambiguidades associadas com a origem da radiação emitida pela rocha (Rider, 1990) e pode apresentar baixa precisão em sucessões argilosas como a Formação Ponta Grossa.

0 estudo integrado do testemunho do poço 2-TB-1-PR, adquirido na região de Tibagi (PR), borda leste da Bacia do Paraná, e de suas curvas de raio-gama total e espectral tem como objetivo a caracterização litológica e gamaespectrométrica das rochas recuperadas, bem como o reconhecimento das unidades siluro-devonianas da Bacia do Paraná em subsuperfície, com a finalidade de contribuir para o conhecimento da bacia, tornando as interpretações litológicas realizadas com base em perfis de poços mais precisas, além de subsidiar futuras discussões litoestratigráficas locais, principalmente com relação aos contatos basal e superior da Formação Ponta Grossa.

\section{2 Área de estudo, material e métodos}

\subsection{Localização da área e contextualização geológica}

O poço 2-TB-1-PR está localizado no leste do Estado do Paraná, a cerca de 16 km da cidade de Tibagi. A principal via que corta a região é a BR-153, rodovia Transbrasiliana, no entanto, partindo da cidade de Tibagi, o acesso é feito preferencialmente pela Rua Frei Gaudêncio e estradas vicinais.

Tratando-se do substrato litológico, a região é reconhecida pelos afloramentos de rochas siluro-devonianas da Supersequência Paraná, que inclui as formações Furnas e Ponta Grossa (Milani et al., 2007) e pelas escarpas formadas por depósitos periglaciais do Grupo Itararé, que correspondem a porção mais basal da Supersequência Gondwana I (Milani et al., 2007) (Figuras 1 e 2).

$$
\text { As rochas da Supersequência }
$$
Paraná assentam-se sobre os estratos 
ordovício-silurianos do Grupo Rio Ivaí, mas também podem ser encontradas diretamente sobre o embasamento. O topo da Supersequência é definido por uma discordância regional desenvolvida no final do Devoniano e, sobretudo, no Carbonífero, quando o Gondwana sul-ocidental experimentou extensa glaciação continental. Esta discordância reflete-se no registro estratigráfico como uma significativa lacuna entre os depósitos microclásticos neodevonianos da Formação Ponta Grossa e os conglomeráticos neocarboníferos do Grupo Itararé (Milani et al., 2007) (Figura 2).

A Formação Furnas pode ser dividida em três intervalos informais caracterizados por associações faciológicas distintas (Assine, 1999). O intervalo inferior é caracterizado por conglomerados e arenitos médios a muito grossos, ricos em grânulos, que normalmente exibem estratificações cruzadas (planares e por onda), estratificações plano paralelas e estratificações do tipo espinha de peixe
(Assine, 1999; Bergamaschi, 1999), interpretado como produto da deposição em sistema litorâneo a marinho-costeiro, afetado por fortes ondas e correntes (Borghi, 1993; Bergamaschi, 1999).

No intervalo intermediário nota-se uma diminuição na incidência e espessura das camadas de conglomerado, bem como uma diminuição na granulometria dos arenitos. Delgados níveis de siltito, que podem exibir laminações cruzadas por onda e icnogêneros da icnofácies Cruziana, são observados. Segundo Assine (1999), estes depósitos correspondem a ambientes marinhos costa-afora dominado por marés, enquanto Bergamaschi (1999) assume que o sistema marinho raso, representado pelo intervalo inferior, está associado lateral e verticalmente a sistemas parálicos, cujo comportamento fora controlado pela criação de espaço de acumulação, seja por causas tectônicas ou eustáticas, ou ainda, por mudanças no aporte sedimentar.

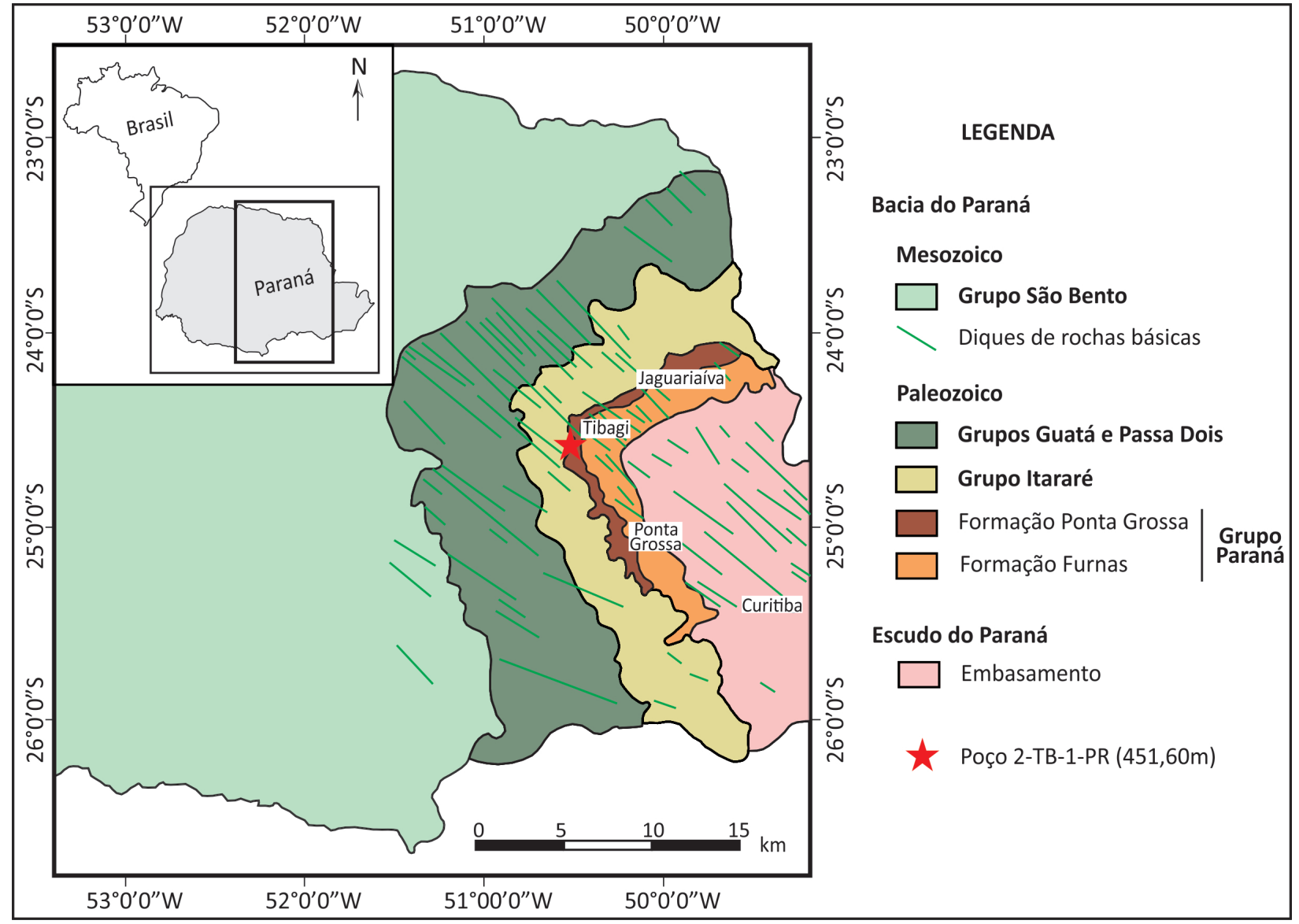

Figura 1. Mapa de localização do poço 2-TB-1-PR (Tibagi) no leste do Estado do Paraná, região do Arco de Ponta Grossa, com indicação das principais cidades próximas e das unidades estratigráficas aflorantes (modificado de Silva \& Vaine, 2001).

Figure 1. Location map of the 2-TB-1-PR (Tibagi) well in eastern Paraná State, Ponta Grossa Arch region, with indication of major nearby cities and outcropping stratigraphic units (modified from Silva \& Vaine, 2001). 


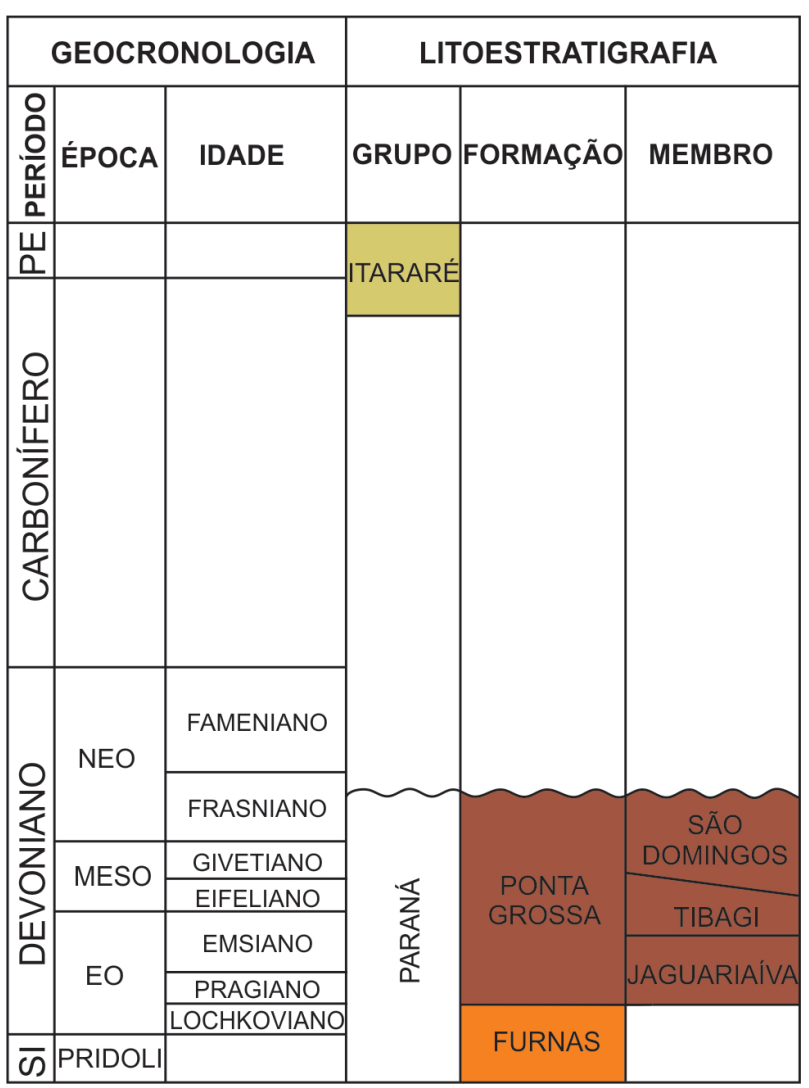

Figura 2. Diagrama crono-litoestratigráfico com ênfase nas unidades estratigráficas aflorantes no leste do Estado do Paraná, região do Arco de Ponta Grossa, Bacia do Paraná. $\mathrm{SI}=$ Siluriano; $\mathrm{PE}=$ Permiano (simplificado de Milani et al., 2007).

Figure 2. Chrono-lithostratigraphic diagram with emphasis on the outcropping stratigraphic units in eastern Paraná State, Ponta Grossa Arch region, Paraná Basin. SI = Silurian; $P E=$ Permian (simplified from Milani et al., 2007).

Por fim, o intervalo superior caracteriza-se pelo incremento de níveis conglomeráticos e aumento na granulometria dos arenitos. Seu topo é marcado pela incidência de siltitos, que podem apresentar restos de plantas fósseis primitivas e palinomorfos, e de arenitos com laminação cruzada por onda e icnogêneros da icnofácies Skolithos (Borghi, 1993; Fernandes, 1996; Bergamaschi, 1999). Tal intervalo representa a migração de formas de leito sob ação de correntes, intensificadas em superfícies canalizadas, sendo provável que tal dinâmica tenha ocorrido na região costeira, em resposta a ação de maré (Bergamaschi, 1999).

As "camadas de transição" (sensu Petri, 1948), caracterizadas por arenitos finos com estratificação cruzada monticulada (hummocky) e laminação cruzada por ondas intercalados com níveis argilosos, cuja deposição teria ocorrido em ambiente de shoreface inferior, marcam a passagem entre as formações Furnas e Ponta
Grossa.

A Formação Ponta Grossa, constituída essencialmente por rochas sedimentares de granulometria fina $(<0,062 \mathrm{~mm})$, é dividida nos membros Jaguariaíva (Praguiano - Emsiano), Tibagi (Eifeliano) e São Domingos (Givetiano Neofrasniano) (q.v. Lange \& Petri, 1967; Milani et al., 2007).

Imediatamente acima das "camadas de transição" ocorrem os depósitos do Membro Jaguariaíva. Trata-se de siltitos arenosos intensamente bioturbados, siltitos laminados, por vezes observa-se delgadas camadas de arenito muito fıno com estratifıcação cruzada monticulada (hummocky), além de folhelhos finamente laminados, de coloração cinza escura. Tal unidade é interpretada como o registro de um sistema marinho raso dominado por ondas e tempestades (Petri, 1948; Bergamaschi, 1999).

O aumento na proporção de sedimentos arenosos, marcado pela maior representatividade de arenitos finos com laminações cruzadas por onda e estratificação cruzada monticulada (hummocky) e/ou arenitos médios intensamente bioturbados, caracterizam o Membro Tibagi. Estas camadas de arenitos estão organizadas em ciclos coarsening upward, com folhelhos e siltitos com laminações cruzadas por onda na base. Segundo Assine (1996), tais ciclos representam uma progradação deltaica em um Trato de Sistemas de Mar Alto, enquanto Bergamaschi (1999) advoga que as areias do Membro Tibagi foram depositadas em um contexto de queda do nível relativo do mar (regressão forçada).

Os depósitos arenosos do Membro Tibagi, quando presentes, são bruscamente afogados por uma espessa seção de folhelhos negros finamente laminados, siltitos com laminação cruzada por onda, argilitos e siltitos com intercalações centimétricas de arenitos, além de arenitos finos a médios com laminação cruzada por onda e estratificação cruzada monticulada (hummocky), atribuídos ao Membro São Domingos. As características dos depósitos apontam para a implantação de uma plataforma marinha rasa, dominada pela ação de ondas, que representa uma importante inundação marinha na bacia (Bergamaschi, 1999; Bergamaschi \& Pereira, 2001; Milani et al., 2007). 


\subsection{Material de estudo e métodos de análise}

O material de estudo consta do testemunho de sondagem do poço 2-TB-1-PR (Tibagi), obtido por sondagem rotativa na Fazenda Vale dos Pássaros, bairro São Domingos, município de Tibagi, estado do Paraná (coordenadas geográficas $24^{\circ} 33^{\prime}$ 45,96"S e 50³0' 58,20"W, datum WGS 84) (Figura 1).

A sondagem alcançou 451,60 m de profundidade e apresenta uma recuperação total de $97 \%$ (Ca. 438,00 m). O testemunho foi descrito na escala 1:40, observando-se, com auxílio do estereomicroscópio Zeiss Stemi 2000C, aspectos texturais (litologia, argilosidade, granulometria, seleção e, quando possível, arredondamento) e composicionais (mineralogia); foram identificadas cores (segundo a escala de cores de Munsell, 2012), tipos de contatos estratais, estruturas sedimentares (hidrodinâmicas e biogênicas), conteúdo fossilífero e índice de icnotrama (sensu Droser \& Bottjer, 1986; 1991). Os dados descritivos foram carregados no software CorelDraw ${ }^{\circledR}$ para elaboração de perfil litológico simplificado (escala 1:800).

Foram realizadas medições pontuais de Tório (Th) eUrânio (U) em partes por milhão (ppm), de Potássio (K) em porcentagem (\%) e de raiogama total (GR) em API em intervalos regulares de aproximadamente $25 \mathrm{~cm}$ ao longo de todo o testemunho de sondagem. Para tal, utilizou-se um espectrômetro de raios-gama portátil modelo RS 230 e, para manter a precisão do método, padronizou-se um tempo de contagem de $240 \mathrm{~s}$ (4 min) para cada medição.

Os resultados obtidos foram carregados no software Microsoft Excel®, normalizados segundo a média e o desvio padrão e, as curvas, suavizadas com médias móveis de cinco pontos. A partir disto, calculou-se as razões Tório/Potássio (Th/K), Tório/Urânio (Th/U) e Urânio/Potássio (U/K), dando ênfase a razão Th/K, utilizada para a realização de inferências mineralógicas (Th/K entre 2 e 3,5 marcam a presença de illita, enquanto as razões $T h / K$ > 3,5 indicam que, além da illita, caolinita e montmorilonita também podem estar presentes - q.v. El Sharawy \& Nabawy, 2016) e Th/U, importante para definir condições paleoambientais (Th/ $\mathrm{U}<2$ indicam condições anóxicas, enquanto $2<\mathrm{Th} / \mathrm{U}<7$ condições disóxicas e Th/U > 7 ocorre tipicamente sob condições oxidantes - q.v. Adams \& Weaver, 1958).

Para auxiliar na observação dos principais comportamentos da curva de raio-gama total (GR), calculou-se, através do software "The $R$ Project for Statistical Computing" versão 3.6.1 (Action of the Toes), a derivada de GR em função da profundidade ( $d \mathrm{Gr} / d$ Prof. q.v. Dalgaard, 2008). O cálculo foi realizado em 100 intervalos com espaçamentos regulares de 4,5 m e, para a interpretação, utilizou-se apenas o sinal dos valores obtidos, que, quando positivos $(+)$, representam uma curva com tendência crescente e, quando negativos (-), indicam curva com tendência decrescente.

A fim de avaliar a aplicabilidade da espectrometria de raios-gama para a classificação de rochas em sucessões argilosas e, se admissível, formular modelos de predição litológica, o software " $R$ " versão 3.6.1 foi utilizado para calcular os parâmetros estatísticos das litologias descritas ao longo do testemunho e para a realização de testes de confiança (Teste-t e ANOVA).

Para a realização do Teste-t, que avalia a similaridade entre pares, é necessário garantir que a distribuição do dado seja normal, que a amostra contenha mais de 30 elementos e que seja menor do que $10 \%$ da população total, além de ser independente e apresentar uma variância constante. Garantidas as condições de validade do modelo estatístico, o teste foi realizado com um intervalo de confiança de 95\%, conforme postulado por Koch \& Link (1970), Cheeney (1983), Stephens (1998) e Diez et al. (2014).

Já o teste ANOVA, realizado de acordo com o proposto por Koch \& Link (1970), Cheeney (1983) e Diez et al. (2014), permite comparar múltiplos grupos simultaneamente e utiliza todos os dados adquiridos. Para tal, é necessário garantir que a variável dependente seja contínua e que a mesma siga uma distribuição normal, além de haver homogeneidade entre as variâncias. Ao obter um valor significativo no teste ANOVA é recomendado a realização de comparações múltiplas, neste caso, tais comparações 
foram realizadas através da função "Pairwise comparisons" do software " $R$ ", que permite executar o Teste-t levando em consideração todos os dados disponíveis e aplicar a Correção de Bonferroni (q.v. Stephens, 1998), o que torna o teste mais rigoroso devido à realização do ajuste do valor de significância em função do número de comparações realizadas.

Utilizando-se de análises palinológicas realizadas a partir de amostras coletadas nas porções basal, mediana e superior do testemunho, abrangendo os intervalos atribuídos as "camadas de transição" e a Formação Ponta Grossa, realizou-se um estudo preliminar de idades. As amostras foram processadas em laboratório para separação e concentração da matéria orgânica de acordo com a metodologia padrão estabelecida pela Petrobras (q.v. Quadros \& Melo, 1987) e as idades estabelecidas a partir da classificação de espécies de esporos e corroboradas com espécies de quitinozários, acritarcos e prasinófitas, todos identificados em lâmina palinológica através do microscópio Zeiss Axioscope A1 em luz transmitida, refletida e fluorescente.

\section{Resultados}

\subsection{Caracterização litológica}

Com base nos aspectos texturais, estruturas sedimentares, tipos de contatos estratais, espessura e recorrência de camadas de arenito e/ou rochas com acamamento heterolítico foi possível distinguir cinco intervalos litológicos ( $A, B, C, D$ e E) para o testemunho do poço 2-TB-1-PR (Quadro 1 e Figura 3).

\subsubsection{Intervalo A $(438,80 m-451,60 m)$}

O Intervalo A compreende $\sim 3 \%$ do testemunho e é caracterizado pela ocorrência exclusiva de arenitos com estratificação cruzada planar (Figura 3). Os arenitos apresentam coloração esbranquiçada a levemente amarelada/acinzentada (white 2.5Y 8/1), exibem baixo grau de bioturbação (índice de icnotrama 1 - 2) (Figura 4A) e estão frequentemente fraturados, sendo a maior densidade de fraturas encontrada em sua porção basal $(451,60 m-448,20 m)$.

Quadro 1. Síntese dos intervalos litológicos descritos no testemunho do poço 2-TB-1-PR e sua correlação com unidades litoestratigráficas.

Chart 1. Synthesis of the lithological intervals described in the drill core 2-TB-1-PR and its correlation with lithostratigraphic units.

\begin{tabular}{|c|c|c|}
\hline $\begin{array}{l}\text { Intervalos } \\
\text { litológicos }\end{array}$ & Descrição & $\begin{array}{l}\text { Unidade } \\
\text { litoestratigráfica } \\
\text { correspondente }\end{array}$ \\
\hline $\begin{array}{c}E \\
(0,00- \\
13,00 \mathrm{~m})\end{array}$ & $\begin{array}{c}\text { Siltitos, siltitos arenosos, arenito lamoso levemente } \\
\text { conglomerático e conglomerado matriz sustentado de coloração } \\
\text { amarelada / alaranjada }\end{array}$ & Grupo Itararé \\
\hline $\begin{array}{c}D \\
(13,00- \\
208,10 \mathrm{~m})\end{array}$ & $\begin{array}{c}\text { Argilitos e siltitos argilosos laminados, rochas com acamamento } \\
\text { heterolítico lenticular e fláser, arenitos bioturbados e arenitos } \\
\text { com laminações plano paralelas e/ou estratificações cruzadas por } \\
\text { onda e, com menor frequência, estratificações cruzadas } \\
\text { monticuladas (hummocky) }\end{array}$ & \multirow[t]{2}{*}{$\begin{array}{c}\text { Formação Ponta } \\
\text { Grossa }\end{array}$} \\
\hline $\begin{array}{c}\text { C } \\
(208,10- \\
432,60 \mathrm{~m})\end{array}$ & $\begin{array}{l}\text { Argilitos e siltitos argilosos laminados, siltitos areno-argilosos e } \\
\text { arenosos bioturbados, rochas com acamamento heterolítico } \\
\text { lenticular e delgadas camadas de arenitos bioturbados }\end{array}$ & \\
\hline $\begin{array}{c}B \\
(432,60- \\
438,80 \mathrm{~m})\end{array}$ & $\begin{array}{l}\text { Arenitos finos que ora apresentam laminações plano paralelas ora } \\
\text { laminações cruzadas por onda e, com menor frequência, } \\
\text { estratificações cruzadas monticuladas (hummocky), intercalados } \\
\text { com argilitos e siltitos }\end{array}$ & \multirow{2}{*}{$\begin{array}{l}\text { Formação } \\
\text { Furnas }\end{array}$} \\
\hline $\begin{array}{c}\text { A } \\
(438,80- \\
451,60 \mathrm{~m})\end{array}$ & $\begin{array}{l}\text { Arenitos predominantemente grossos, de coloração } \\
\text { esbranquiçada a acinzentada, com estratificação cruzada planar }\end{array}$ & \\
\hline
\end{tabular}




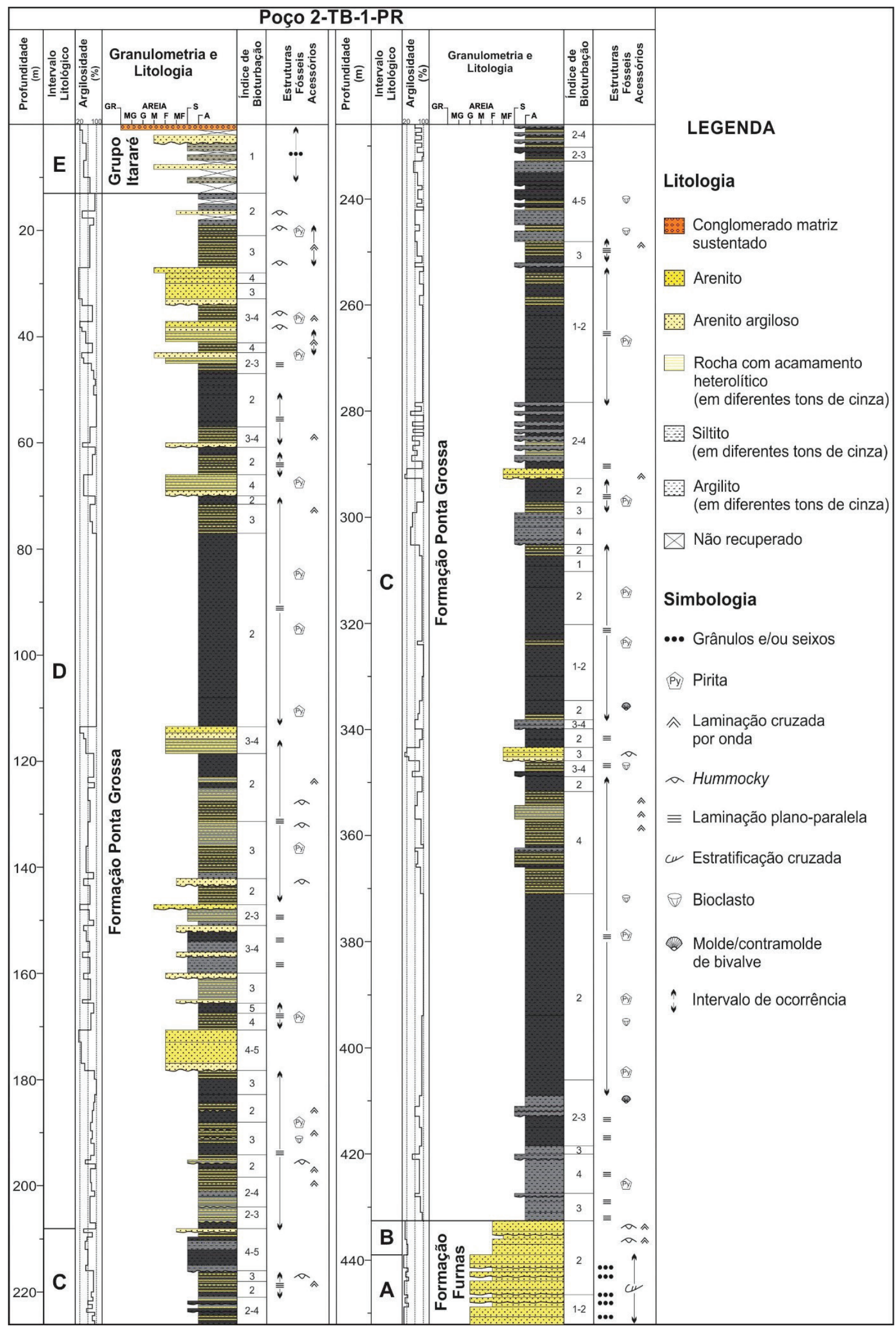

Figura 3. Perfil litológico simplificado (escala 1:800) do testemunho do poço 2-TB-1-PR, com destaque para os cinco intervalos litológicos identificados (A, B, C, D e E) e as unidades litoestratigráficas correspondentes.

Figure 3. Simplified lithological profile (1:800 scale) of the drill core 2-TB-1-PR, highlighting the five lithological intervals identified $(A, B, C, D$ and $E)$ and the corresponding lithostratigraphic units. 
Há um amplo predomínio de camadas métricas de arenitos grossos (Figura 3), mal selecionados, com grãos subangulosos, de composição quartzosa e com argilosidade inferior a 10\%; micas (muscovita e biotita) ocorrem de forma subordinada. Estratificações cruzadas planares são caracterizadas por variações granulométricas e/ou mineralógicas e o contato basal das camadas, frequentemente erosivo, é marcado por pavimentos de grânulos e seixos (Figura 4B).

Camadas centimétricas de arenitos finos, moderadamente selecionados, subangulosos, de composição quartzosa, intercalam-se aos arenitos grossos (Figura 3). Apresentam argilosidade variando entre 15 e 25\%, estratificações cruzadas planares e laminações plano paralelas marcadas por concentrações de biotita, além de delgados níveis de argilitos pretos e siltitos esverdeados (Figura 4C).

\subsubsection{Intervalo $B(432,60 m-438,80 m)$}

O Intervalo B é o mais restrito, correspondendo a $\sim 1,5 \%$ do testemunho analisado (Figura 3). É caracterizado por camadas centimétricas a métricas de arenitos que ora exibem laminações plano paralelas ora laminações cruzadas por onda e, de modo mais restrito, estratificações cruzadas monticuladas (hummocky), intercalados com níveis milimétricos a centimétricos de argilitos e siltitos pretos (Figura 5A).

Os arenitos são predominantemente finos, apresentam coloração variando de acinzentada (light gray $2.5 \mathrm{Y} 7 / 2$ e $7 / 1$ e gray $2.5 \mathrm{Y}$ 6/1) a levemente acastanhada (light yellowish brown 2.5 Y 6/3), bem selecionados, com grãos subarredondados, decomposiçãoessencialmente quartzosa, com presença de muscovita e biotita. Apresentam-se pouco bioturbados (índice de icnotrama 2) e com argilosidade variando entre 10 e $20 \%$. Argilosidade mais elevada ( 25-35\%) pode ser identificada em alguns níveis e está associada a processos de incorporação de finos por ação biogênica. As estruturas sedimentares são marcadas preferencialmente pelo acúmulo de micas.

\subsubsection{Intervalo C $(208,10 m-432,60 m)$}

O Intervalo C compreende $\sim 50 \%$ do testemunho analisado e é caracterizado por espessas camadas de argilitos, siltitos, rochas com acamamento heterolítico lenticular e delgadas camadas de arenitos (Figura 3). Seu contato com o topo do Intervalo B é marcado pela brusca mudança litológica e de cor e, também, pela presença de um pavimento de grânulos e seixos finos (Figura 5B).

Argilitos sílticos, moderadamente bioturbados e de coloração cinza clara (Figura 5C) ocorrem exclusivamente na porção basal do intervalo (Figura 3), argilitos e argilitos sílticos finamente laminados, pouco bioturbados (índice de icnotrama 1 - 2), bem selecionados e de coloração predominantemente cinza escura / preta (gray 2.5Y 5/1; dark gray 2.5Y 4/1; very dark gray $2.5 \mathrm{Y} 3 / 1$ e black $2.5 \mathrm{Y}$ 2.5/1) (Figura $5 D)$, estão presentes em camadas métricas ao longo de todo o intervalo (Figura 3). Bioclastos carbonáticos, por vezes piritizados, bem como seus moldes e contramoldes, foram descritos exclusivamente nesta litologia.

Siltitos variando de areno-argilosos a arenosos, intensamente bioturbados (índice de icnotrama 4 - 5) e moderadamente selecionados (Figura 5E) ocorrem em camadas centimétricas a métricas ao longo de todo o intervalo, no entanto, são mais recorrentes em sua porção superior (305,00 m - 208,10 m) (Figura 3). Apresentam coloração variando em tons de cinza (gray $2.5 \mathrm{Y}$ $5 / 1$ e $6 / 1$ e dark gray $2.5 Y$ 4/1) e argilosidadade entre 55 e $75 \%$.

Rochas com acamamento heterolítico lenticular (linsen bedding), dado por intercalações entre argilito / siltito argiloso (60 - 85\%) e arenito muito fino (40\% - 15\%) (Figuras 5F e 5G), ocorrem em camadas centimétricas, normalmente associadas com argilitos finamente laminados (Figura 3). Apresentam predomínio de cor cinza escura (gray 2.5Y 5/1; dark gray 2.5Y 4/1 e very dark gray 2.5Y 3/1) e índice de icnotrama 2 - 4. Quanto menor o índice de icnotrama, mais fácil a identificação de estruturas sedimentares, tais quais: laminações plano paralelas, laminações cruzadas por onda e, mais raramente, estratificações cruzadas monticuladas 
(hummocky). Na base dos níveis de arenito é comum a ocorrência de feições erosivas, como gutter casts.

Os arenitos são pouco frequentes no Intervalo C e ocorrem em raras camadas delgadas (Figura 3). Trata-se de arenitos e arenitos argilosos, com argilosidade variando entre 10 e 30\%, finos a muito finos, quartzosos, intensamente bioturbados (índice de icnotrama 4 - 5), bem a moderadamente selecionados, subangulosos e de coloração acinzentada (light gray 2.5Y 7/1 e 7/2 e gray 2.5Y 5/1 e 6/1) (Figura $5 \mathrm{H}$ ). Por vezes, apresenta índice de icnotrama 2, o que permite identificar laminações plano paralelas, laminações cruzadas por onda e, mais raramente, estratificações cruzadas monticuladas (hummocky).

\subsubsection{Intervalo $D(13,00 m-208,10 m)$}

O Intervalo D é o segundo mais expressivo, correspondendo a $\sim 43 \%$ do testemunho analisado, e, assim como o Intervalo C, é caracterizado por espessas camadas de argilitos e argilitos sílticos finamente laminados, no entanto, apresenta maior proporção de rochas areníticas e de rochas com acamento heterolítico (Figura 3).
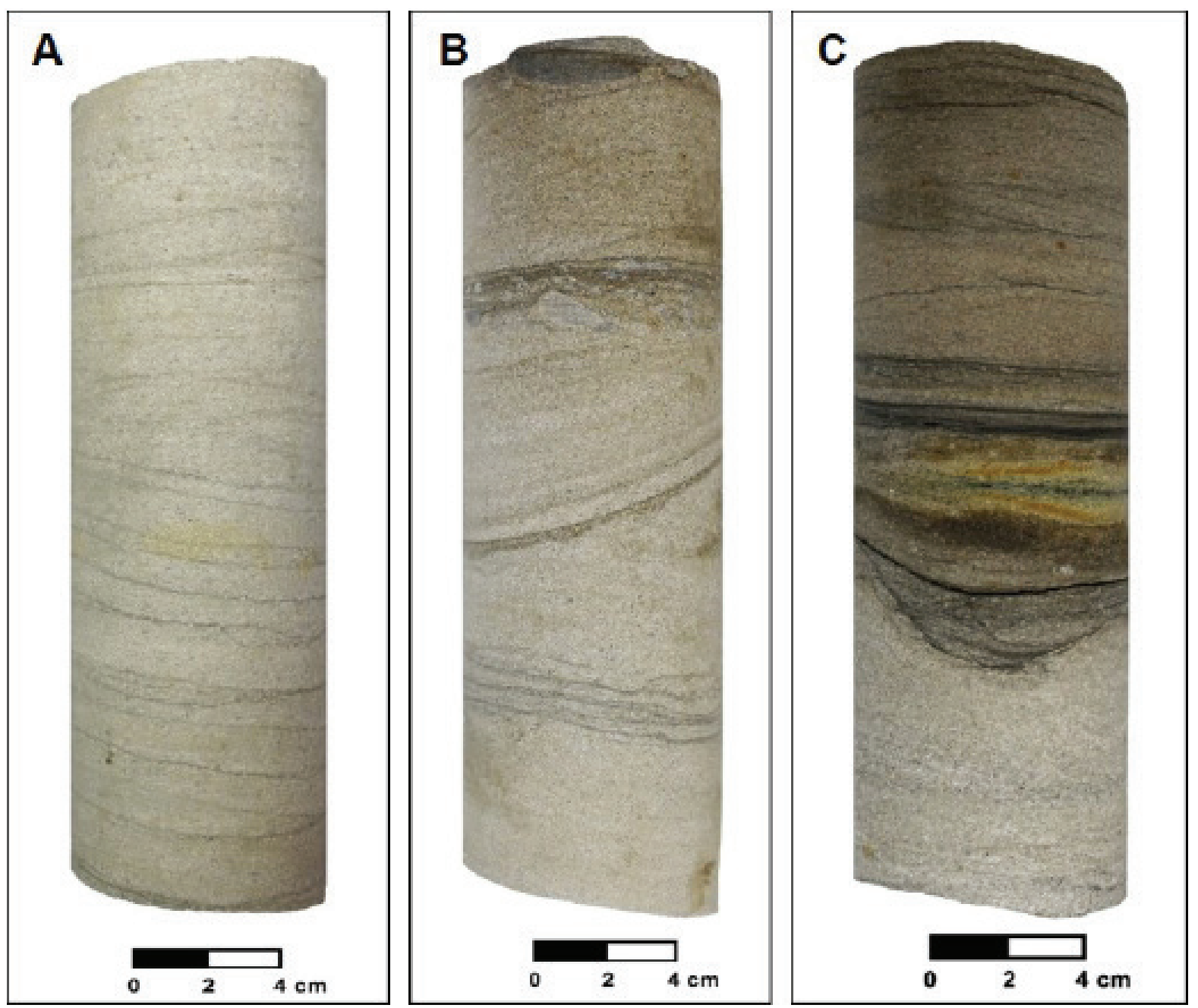

Figura 4. Aspecto geral das rochas do Intervalo A. A) Arenito grosso com estratificação cruzada planar com coloração levemente amarelada; B) Note na parte superior da amostra contatos erosivos marcados por pavimentos de grânulos e seixos; e C) Note na parte central da amostra uma lente de siltito esverdeado e delgados níveis de argilito preto marcando o contato entre o arenito grosso (presente na base) e o arenito fino.

Figure 4. Overview of the rocks in Interval A. A) Coarse sandstone with planar cross-stratification and slightly yellowish color; B) Note, at the top of the sample, erosive contacts marked by granule and pebble floors; and C) Note, in the central part of the sample, a greenish silt lens and thin levels of black mudstone marking the contact between coarse sandstone (present at the base) and fine sandstone. 

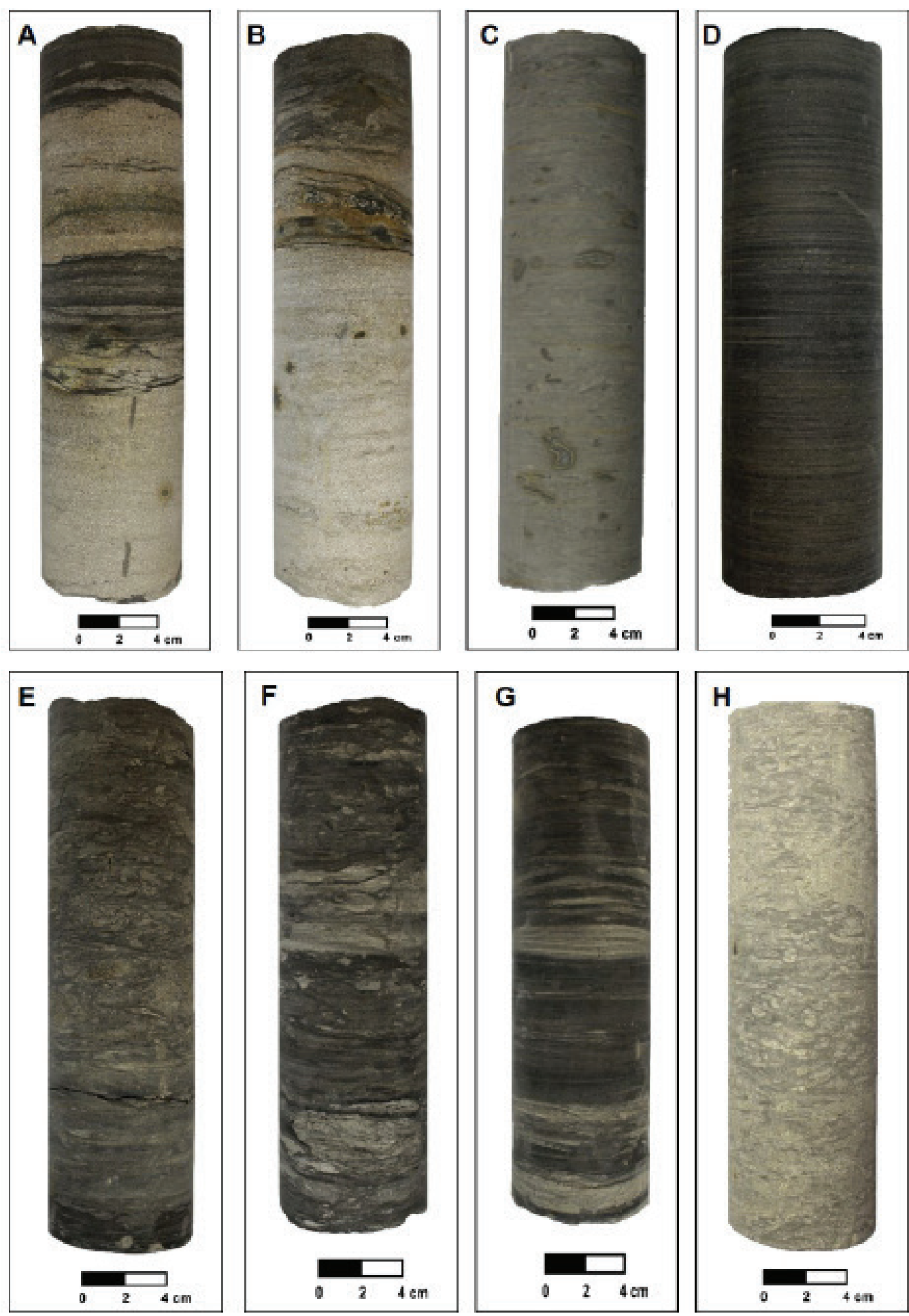

Figura 5. Aspecto geral das rochas dos intervalos B e C. A) Arenito intercalado com níveis mili- a centimétricos de argilito, típico do Intervalo B; B) Note na parte superior da amostra um nível de grânulos e seixos finos que ajudam a marcar o limite entre os intervalos B (base da amostra) e C (topo da amostra); C) Argilito síltico típico da base do Intervalo C; D) Argilito laminado; E) Siltito areno-argiloso intensamente bioturbado; F e G) Variações das rochas com acamamento heterolítico lenticular, em F) observa-se maior proporção de arenito e maior grau de bioturbação e em $\mathrm{G}$ ) menor proporção de arenito, menor grau de bioturbação e melhor preservação de estruturas hidrodinâmicas; e H) Arenito intensamente bioturbado.

Figure 5. Overview of the rocks in intervals B and C. A) Sandstone interleaved with millimeter to centimeter levels of claystone, typical of Interval B; B) Note, at the top of the sample, a level of granules and fine pebbles that help to mark the boundary between intervals B (sample's base) and C (sample's top); C) Silty claystone typical from the base of Interval C; D) Laminated claystone; E) Intensely bioturbated silty-sandy claystone; $F$ and G) Variations of rocks with linsen bedding, in F) there is a higher proportion of sandstone and a higher bioturbation index and in $\mathrm{G}$ ) a smaller proportion of sandstone, a lower bioturbation index and a better preservation of hydrodynamic structures; and $\mathrm{H}$ ) Intensely bioturbated sandstone. 
O contato com o Intervalo $C$ é dado pela transição entre siltitos arenosos e argilitos laminados. Os argilitos e argilitos sílticos laminados do Intervalo D (Figura 6A) são similares aos descritos para o Intervalo $C$, enquanto que, as rochas com acamamento heterolítico, além de mais frequentes, apresentam maior variação entre as proporções de argilito (35 - 85\%) e arenito (65 - 15\%), sendo classificadas como lenticular (linsen bedding) (Figura 6B) e fláser (flaser bedding) (Figura 6C).

Bem como as do Intervalo $\mathrm{C}$, as rochas com acamamento heterolítico do Intervalo D apresentam desde níveis intensamente bioturbados (índice de icnotrama 4) até níveis com estruturas sedimentares, como laminações plano paralelas, laminações cruzadas por onda e estratificações cruzadas monticuladas (hummocky), bem preservadas. Superfícies erosivas são frequentemente observadas na base dos níveis de arenito.

Arenitos e arenitos argilosos (argilosidade entre 15 e 35\%) ocorrem ao longo de todo o intervalo em camadas centimétricas a métricas (Figura 3). São preferencialmente finos, moderadamente selecionados, subangulosos a subarredondados, de composição essencialmente quartzosa, com presença de biotita e muscovita. Exibem coloração acinzentada (gray 2.5Y 5/1 e 6/1; light gray $2.5 \mathrm{Y} 7 / 1$ e $7 / 2$ e light brownish gray $2.5 \mathrm{Y} 6 / 2$ ) e, normalmente, apresentam-se intensamente bioturbados (índice de icnotrama 4) (Figura 6D). Encontram-se dispostos sobre depósitos argilosos, o que permite identificar com facilidade o contato basal erosivo (Figura 6E), além de estruturas de carga (load casts) e chama (flame structures).

Por vezes, os arenitos apresentam índice de icnotrama 1 - 2, preservando laminações plano paralelas e, mais raramente, laminação cruzada por onda (Figura 6F) e estratificação cruzada monticulada (hummocky).

\subsubsection{Intervalo $E(0,00 m-13,00 m)$}

O Intervalo E corresponde a $\sim 3 \%$ do testemunho analisado e torna-se ainda menos expressivo devido a recuperação de apenas
$47 \%$, o que corresponde a cerca de $6,00 \mathrm{~m}$ de testemunho (Figura 3). Por se tratar do intervalo mais superficial, o mesmo encontra-se alterado por processos pedogenéticos, responsáveis pela elevada argilosidade e pelo aspecto mosqueado.

A base do Intervalo E é constituída por siltitos e siltitos arenosos, moderadamente a mal selecionados, com aspecto mosqueado dado por manchas amareladas (very pale brown 10YR $7 / 3,7 / 4$ e 8/4) (Figura 7A) que obliteram suas características primárias. A argilosidade varia entre 55 e 75\%, dentre a fração macroclástica observa-se predomínio de areia grossa, angulosa, de composição quartzo-feldspática, além de grânulos de quartzo.

Sobre as camadas de siltito ocorre arenito médio lamoso (argilosidade variando entre 30 e 35\%) maciço, moderadamente a mal selecionado, subanguloso, de composição essencialmente quartzosa. Apresenta coloração alaranjada / amarelada (reddish yellow 7.5YR 6/6 e 7/6), com aspecto mosqueado. Grânulos e seixos finos, de composição predominantemente quartzosa, com raros grãos de feldspato e litoclastos máficos, são frequentemente observados (Figura 7B).

No topo do intervalo observa-se uma camada com $60 \mathrm{~cm}$ de espessura de conglomerado matriz sustentado maciço, mal selecionado, de coloração amarronzada/ alaranjada (strong brown 7.5YR 5/6), constituído por matriz areno-argilosa (25\% de argilosidade) onde há predomínio de areia grossa, subangulosa, de composição quartzosa. Grânulos e seixos, de composição quartzosa, com raros feldspatos e litoclastos metamórficos, são abundantes (Figura 7C).

\subsection{Datação}

A análise preliminar de idades, realizada através de estudo palinológico, indica que o testemunho do poço 2-TB-1-PR, desde as "camadas de transição" até o topo da Formação Ponta Grossa (intervalos litológicos B, C e D), é datado como sendo Neopraguiano - Eo/ MesoGivetiano(?).

Na porção basal do testemunho $(438,70 \mathrm{~m}$ de profundidade), o aparecimento do esporo 

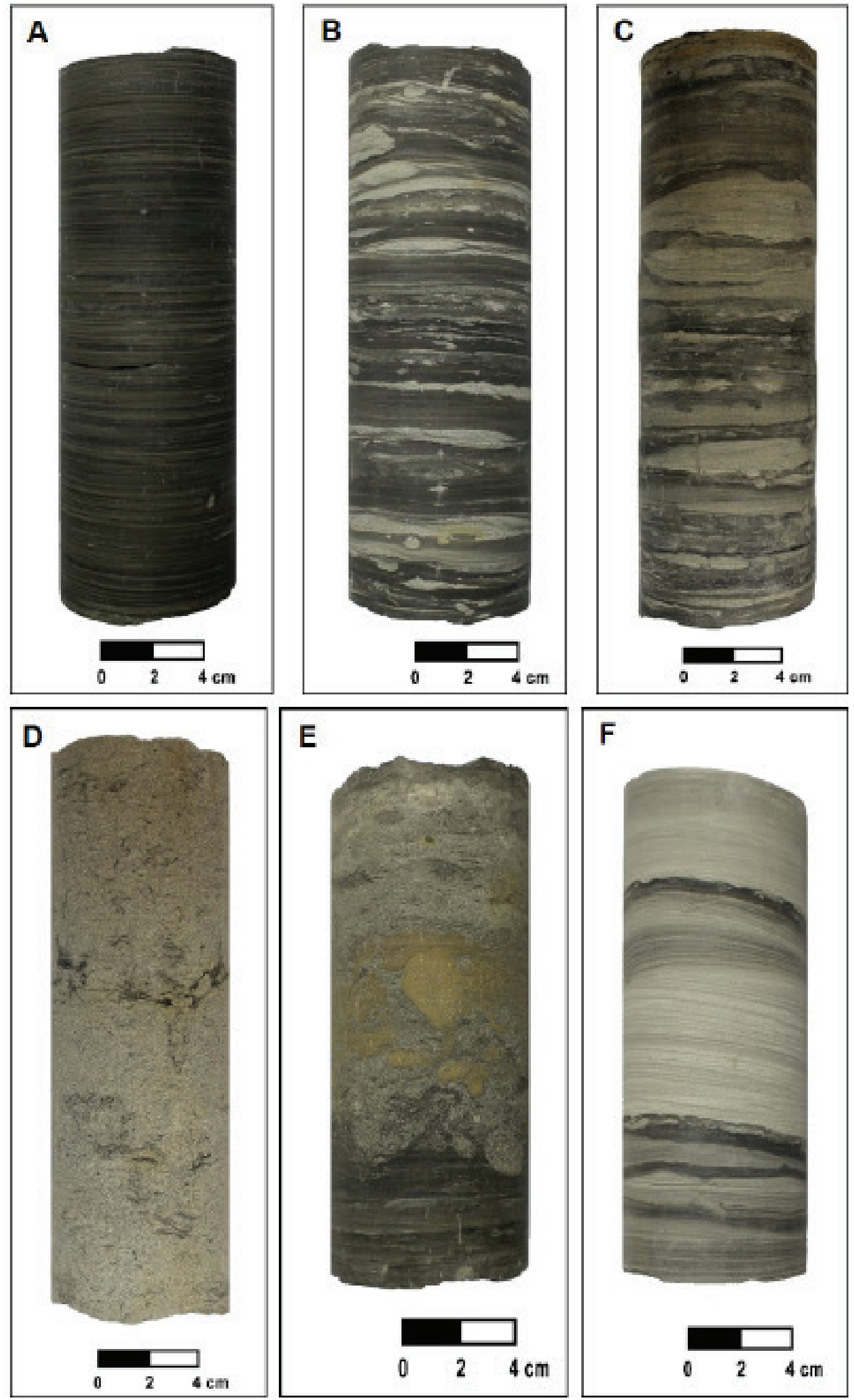

Figura 6. Aspecto geral das rochas do Intervalo D. A) Argilito laminado; B) Rocha com acamamento heterolítico lenticular; C) Rocha com acamamento heterolítico fláser; D) Arenito intensamente bioturbado; E) Contato erosivo entre arenito bioturbado com nódulos de ferro(?) e lamito laminado e F) Arenito com laminação cruzada por onda.

Figure 6. Overview of the rocks in Interval D. A) Laminated claystone; B) Rock with linsen bedding; C) Rock with flaser bedding; D) Intensely bioturbated sandstone; E) Erosive contact between bioturbated sandstone with iron nodules(?) and laminated mudstone and F) Sandstone with wave cross-laminations. 
Dictyotriletes subgranifer (Figura 8) indica o intervalo Neopraguiano/Eoemsiano. Tal idade é corroborada pelas espécies de quitinozoários Ramochitina magnifica, Hoegisphaera sp. cf. H. glabra e Ancyrochitina pachycerata (Figura 8), bem como, pelos acritarcos e prasinófitas Bimerga paulae, Cymatiosphaera cornífera, Evittia remota e Triangulina alargada.

A primeira ocorrência da espécie de esporo Acinosporites lindlarensis (Figura 8) em 315,60 m de profundidade, corroborada pelo surgimento simultâneo do acritarco Evittia somerii, sinaliza a transição entre o final do Emsiano (Neoemsiano) e o início do Eifeliano. Já a passagem do Eifeliano para o Givetiano é caracterizada pela diversificação do complexo Grandispora/Samarisporites spp., que no testemunho do poço 2-TB-1-PR é definida pelo aparecimento de Verrucosisporites premnus (Figura 8), seguido de Emphanisporites annulatus (Figura 8) e Camarozonotriletes concavus, em, respectivamente, 240,50 m, 230,60 m e 225,35 m de profundidade.

0 intervalo Givetiano do referido testemunho é diagnosticado pelo aparecimento do esporo Geminospora lemurata (Figura 8) em 165,20 m de profundidade. Espécies de quitinozoários como Angochitina daemonii (Figura 8), Alpenachitina eisenacki e Ancyrochitina simplex (Figura 8) confirmam tal idade. Samarisporites triangulatus (Figura 8), principalmente quando ocorre em conjunto com Chelinospora paravermiculata e Cymbosporites cyathus, conforme identificado entre $145,65 \mathrm{~m}$ e 15,50 $\mathrm{m}$ do testemunho, indicam idades entre o Eogivetiano e o Eofrasniano. No entanto, espécies de quitinozoários, acritarcos e prasinófitas características do Neogivetiano e do Eofrasniano não foram encontradas, tal ausência, faz com que se restrinja o intervalo de tempo compreendido no testemunho do poço 2-TB-1-PR ao Eo/ MesoGivetiano(?).
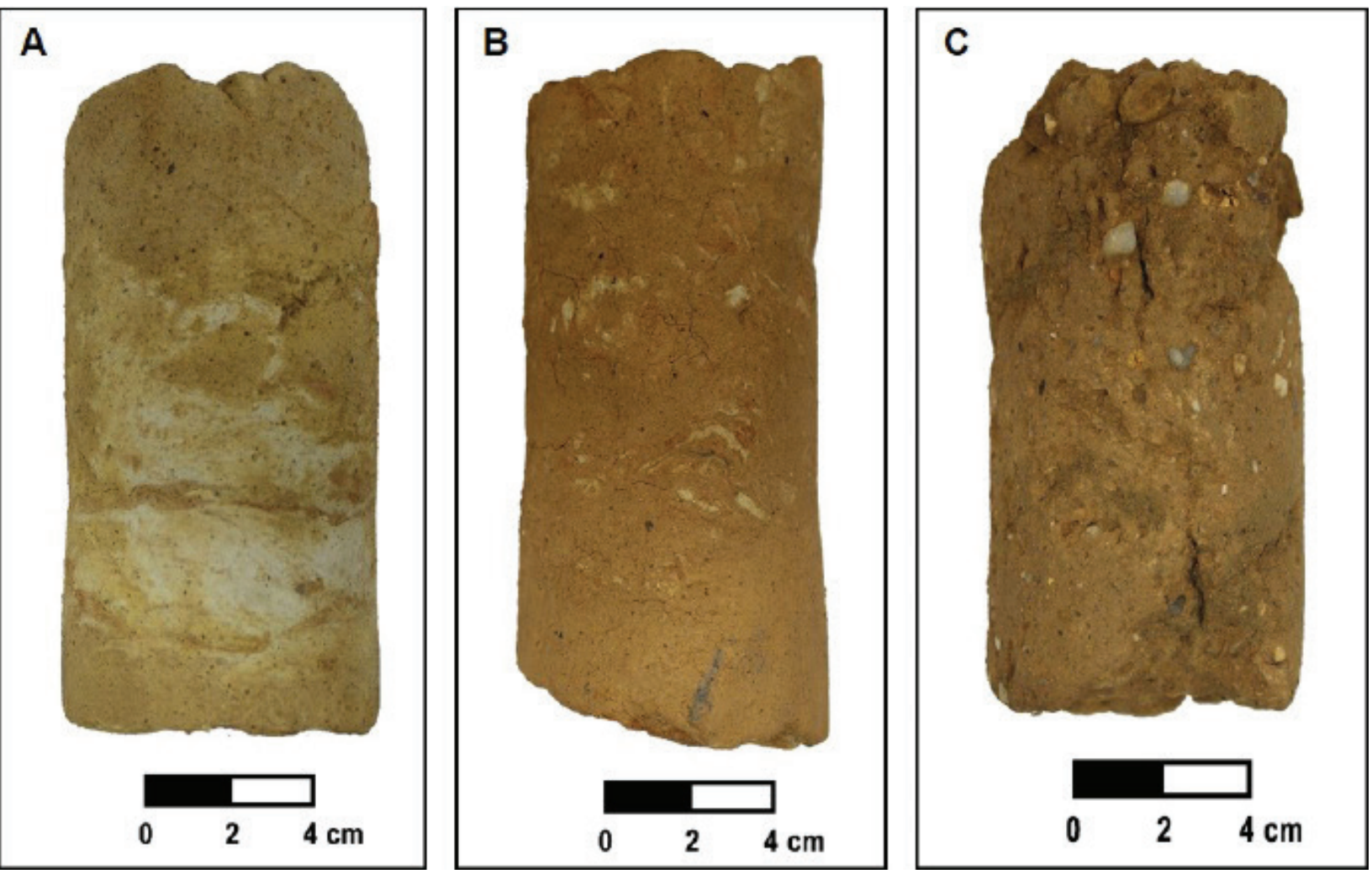

Figura 7. Aspecto geral das rochas do Intervalo E. A) Siltito arenoso com manchas amareladas; B) Arenito médio lamoso com coloração alaranjada; e C) Conglomerado matriz sustentado com grânulos e seixos finos de quartzo e raros feldspatos.

Figure 7. Overview of the rocks in Interval E. A) Sandy silt with yellowish spots; B) Muddy medium sandstone with orange color; and C) Supported matrix conglomerate with granules and fine pebbles of quartz and rarely feldspars. 


\subsection{Espectrometria de raios-gama}

O testemunho do poço 2-TB-1-PR é constituído essencialmente por espessas seções de argilitos, além de rochas com acamamento heterolítico fláser e lenticular, siltitos, arenitos e arenitos argilosos, estes últimos com > 20\% de argila, e, localmente, ocorrem conglomerados intensamente pedogeneizados (Figura 3). Neste espectro litológico os valores de Th, $U, K$ e raiogama total (GR) variam entre 22,8 - 7,2 ppm, 11,7 - 0,6 ppm, 6,9 - 0,3\% e 284,9 - 133,2 API, respectivamente (Figura 9).

As maiores medições de Th, U, K e GR nos intervalos A (22,4 ppm, 8,6 ppm, 5,2\% e 255,6 API, respectivamente) e B (21,4 ppm, 7,8 ppm, 5,2\% e 264,7 API, respectivamente) estão associadas as camadas de arenitos mais finos, que apresentam maior argilosidade e/ou maior percentual de micas em sua composição. A variação textural descrita nestes intervalos pode ser observada indiretamente através do perfil de GR, que entre 432,60 - 451,60 m apresenta padrões em sino (Figura 9). Já a transição do intervalo A para o B é marcado por uma inversão nos valores da derivada de GR, sendo positivo em A e negativo em B (Figura 9).

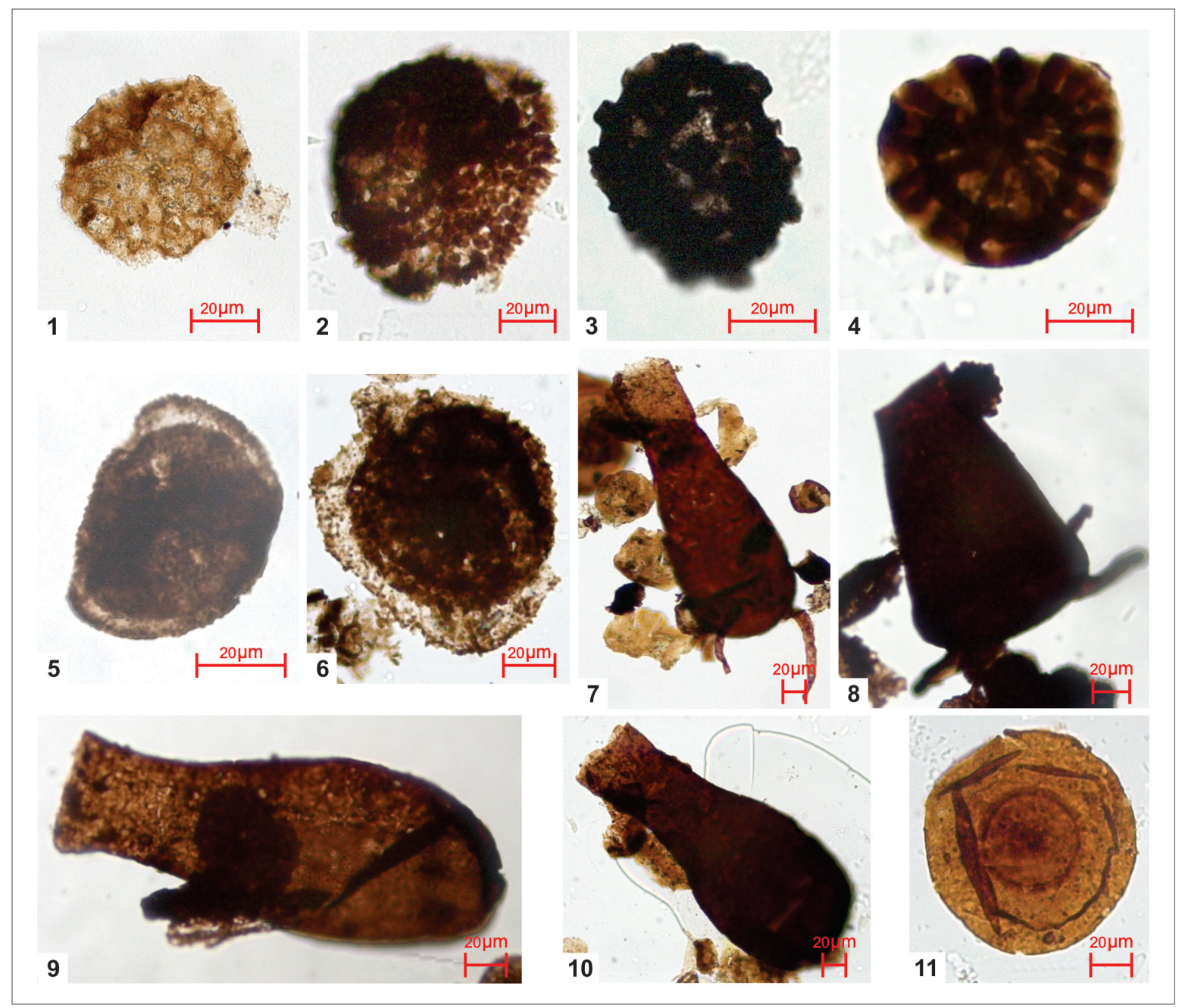

Figura 8. Principais palinomorfos utilizados para datação dos intervalos litológicos $B, C$ e $D$ do testemunho do poço 2-TB-1-PR, correspondentes as "camadas de transição" e a Formação Ponta Grossa. Observe em 1) Dictyotriletes subgranifer McGregor, 1973 de 370,60 m de profundidade (EF: 057/1); 2) Acinosporites lindlarensis Riegel, 1968 de 195,35 m de profundidade (EF: H41/1-2); 3) Verrucosisporites premnus Richardson, 1965 de 45,70 m de profundidade (EF: M51/24); 4) Emphanisporites annulatus McGregor, 1961 de 230,60 m de profundidade (EF: N60/1-2); 5) Geminospora lemurata Balme, 1982 emend. Playford, 1983 de 165,20 m de profundidade (EF: M37/2); 6) Samarisporites triangulatus Allen, 1965 de 145,65 m de profundidade (EF: F40); 7) Ancyrochitina pachycerata de 290,45 m de profundidade (EF: L47/3-4); 8) Ancyrochitina simplex de 50,55 m de profundidade (EF: C28/1-2); 9) Angochitina daemonii de 50,55m de profundidade (EF: G56/3); 10) Ramochitina magnifica Lange, 1967 de 385,30 m de profundidade (EF: P46/1-2); e 11) Hoegisphaera sp. cf. H. glabra de 390, $55 \mathrm{~m}$ de profundidade (EF: Q64/3).

Figure 8. Main palynomorphs used for dating the B, $C$ and $D$ lithological intervals of the drill core 2-TB-1-PR, corresponding to the "transition layers" and the Ponta Grossa Formation. 


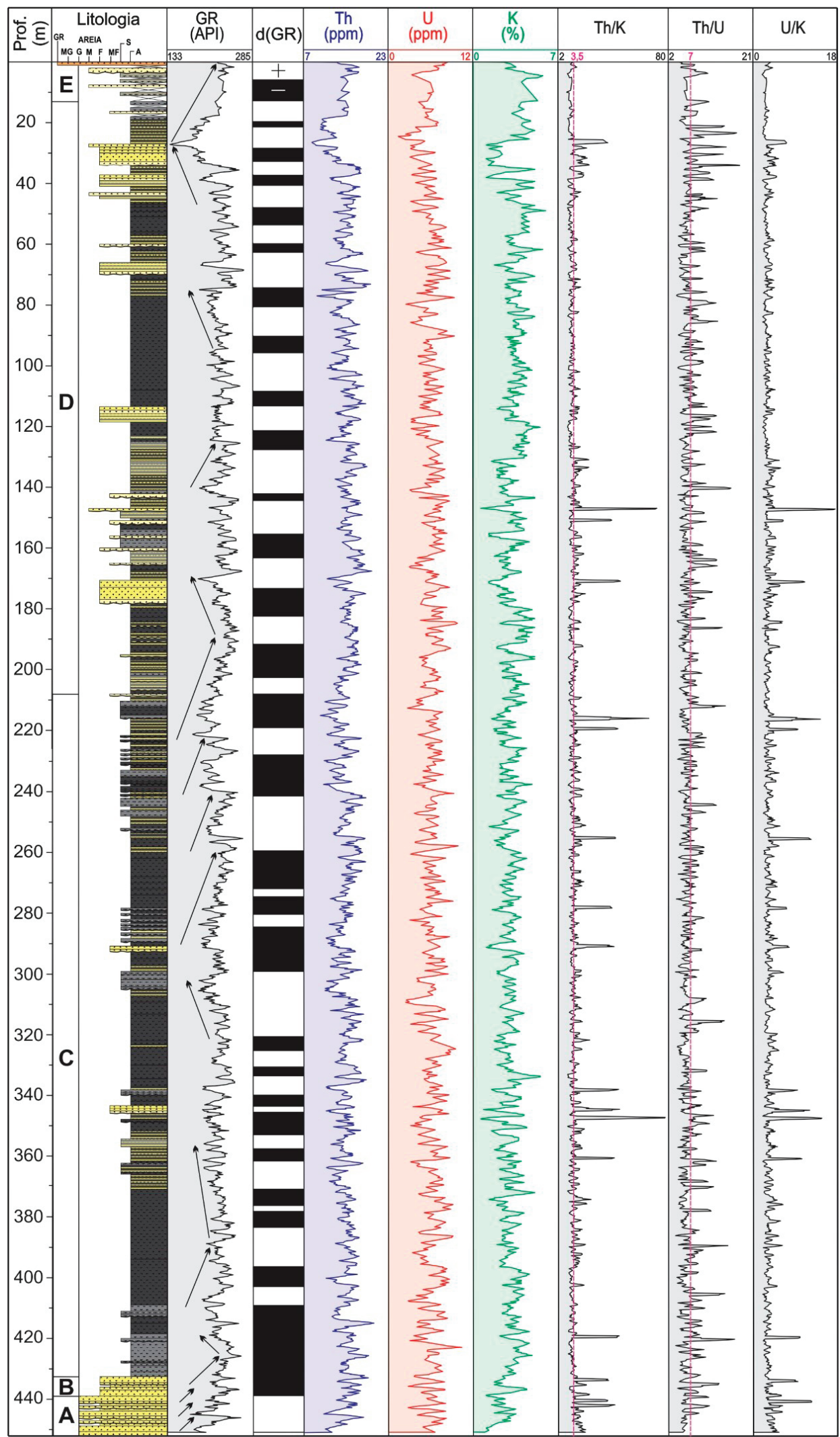

Figura 9. Dados gamaespectrométricos (GR, Th, U e K) e as razões Th/K, Th/U e U/K do testemunho do poço 2-TB-1PR. Note os principais padrões em funil e em sino identificados na curva de GR e os valores positivos (+; em branco) ou negativos (-; em preto) obtidos a partir da derivada de GR. Nas curvas de Th/K e Th/U destaca-se valores importantes para a realização de inferências mineralógicas e interpretação de condições paleoambientais, respectivamente. Observe legenda e perfil litológico detalhado na Figura 3.

Figure 9. Gamma-spectrometric data (GR, Th, $U$ and $K$ ) and the $T h / K, T h / U$ and $U / K$ ratios of the drill core 2-TB-1-PR. Note the main funnel and bell patterns identified in the GR curve and the positive (+; in white) or negative (-; in black) values obtained from the GR derivative. In the Th/K and Th/U curves are highlighted important values for mineralogical inferences and interpretation of paleoenvironmental conditions, respectively. Observe legend and lithological profile detailed in Figure 3. 
Quando comparado com arenitos e arenitos argilosos presentes ao longo de todo o testemunho, os do Intervalo B apresentam as maiores médias de GR (Tabela 1), o que tem relação direta com a intercalação frequente de níveis milimétricos a centimétricos de argilitos e siltitos (Figura 5A).

Nos intervalos litológicos $C$ e $D$, o range de variação dos valores medidos é pequeno e, apesar de ser possível observar padrões em sino e em funil bem marcados (Figura 9) não é possível realizar distinção entre as diferentes litologias descritas, salvo camadas de arenito que apresentam maior espessura. Comparando os valores obtidos para cada uma das litologias descritas para o Intervalo $C$, observa-se médias de Th, U, K e GR inferiores às médias calculadas para as mesmas litologias em todo o testemunho (Tabela 1), tal padrão também pode ser notado pela curva de GR, que se encontra sutilmente deslocada para a direita acima de 208,10 m de profundidade.

Os intervalos C e D apresentam um padrão zebrado, com constante inversão nos valores da derivada de GR, no entanto, em C, as porções com derivada negativa são mais espessas e frequentes, mostrando maior recorrência de tendências decrescentes de GR quando comparada ao D.

Tabela 1. Parâmetros estatísticos calculados através dos dados espectrais de raio-gama para cada uma das litologias descritas ao longo do testemunho do poço 2-TB-1-PR (Test.). Cálculos foram realizados considerando as litologias presentes nos intervalos litológicos B (Int. B: 432,60 - 438,80 m), C (Int. C: 208,10 - 432,60 m) e E (Int. E: 0,00 - 13,00 m). $\mathrm{GR}=$ raio-gama total; $\mathrm{X}=$ média aritmética; $\sigma=$ desvio padrão; $\mathrm{N}=$ número de medições.

Table 1. Statistical parameters calculated by gamma-ray spectral data for each of the lithologies described along the drill core 2-TB-1-PR (Test.). Calculations were performed considering the lithologies present in the lithological intervals $B$ (Int. B: $432.60-438.80 \mathrm{~m}$ ), C (Int. C: $208.10-432.60 \mathrm{~m}$ ) and $E(I n t . E: 0.00-13.00 \mathrm{~m})$. GR = total gamma ray; $X=$ arithmetic mean; $\sigma=$ standard deviation; $N=$ number of measurements.

\begin{tabular}{|c|c|c|c|c|c|c|c|c|c|c|}
\hline \multirow{2}{*}{\multicolumn{2}{|c|}{ Litologia }} & \multicolumn{2}{|c|}{ Th (ppm) } & \multicolumn{2}{|c|}{ U (ppm) } & \multicolumn{2}{|c|}{ K (\%) } & \multicolumn{2}{|c|}{ GR (API) } & \multirow{2}{*}{$\mathbf{N}$} \\
\hline & & $\bar{X}$ & $\sigma$ & $\bar{X}$ & $\sigma$ & $\bar{X}$ & $\sigma$ & $\bar{X}$ & $\sigma$ & \\
\hline Conglomerado & Test. & 15,66 & 0,34 & 6,52 & 0,68 & 2,74 & -- & 195,26 & 3,90 & 3 \\
\hline \multirow{3}{*}{ Arenito } & Test. & 16,50 & 1,61 & 4,74 & 1,30 & 2,40 & 0,94 & 191,40 & 18,84 & 182 \\
\hline & Int. B & 17,73 & 1,68 & 4,52 & 1,30 & 2,86 & 1,03 & 205,66 & 21,12 & 28 \\
\hline & Int. C & 16,48 & 1,37 & 4,72 & 1,45 & 2,27 & 1,03 & 188,13 & 18,99 & 21 \\
\hline \multirow{4}{*}{ Arenito argiloso } & Test. & 16,90 & 1,32 & 4,89 & 1,34 & 3,18 & 0,92 & 205,63 & 15,82 & 95 \\
\hline & Int. B & 16,61 & 0,39 & 7,29 & 0,51 & 3,84 & 0,37 & 223,51 & 9,95 & 3 \\
\hline & Int. C & 15,88 & 1,15 & 4,88 & 1,54 & 3,12 & 0,79 & 199,79 & 14,66 & 11 \\
\hline & Int. E & 17,31 & 1,87 & 5,41 & 1,06 & 3,20 & 0,77 & 211,35 & 13,87 & 9 \\
\hline $\begin{array}{l}\text { Acamamento } \\
\text { heterolítico } \\
\text { fláser }\end{array}$ & Test. & 16,99 & 1,44 & 4,84 & 1,40 & 3,27 & 0,91 & 206,74 & 16,44 & 48 \\
\hline \multirow{2}{*}{$\begin{array}{c}\text { Acamamento } \\
\text { heterolítico } \\
\text { lenticular }\end{array}$} & Test. & 16,95 & 1,47 & 5,13 & 1,26 & 3,15 & 0,91 & 206,52 & 16,63 & 471 \\
\hline & Int. C & 16,65 & 1,41 & 5,10 & 1,24 & 2,92 & 0,87 & 200,45 & 14,72 & 181 \\
\hline \multirow{3}{*}{ Siltito } & Test. & 16,75 & 1,34 & 4,89 & 1,25 & 3,05 & 0,92 & 200,39 & 16,80 & 228 \\
\hline & Int. C & 16,45 & 1,34 & 4,18 & 1,26 & 2,96 & 0,87 & 198,61 & 16,09 & 214 \\
\hline & Int. E & 17,34 & 0,98 & 4,94 & 0,93 & 4,51 & 0,76 & 227,61 & 10,64 & 14 \\
\hline \multirow{2}{*}{ Argilito } & Test. & 17,13 & 1,43 & 5,12 & 1,34 & 3,33 & 0,88 & 209,52 & 15,46 & 843 \\
\hline & Int. C & 17,08 & 1,44 & 5,10 & 1,30 & 3,14 & 0,87 & 207,26 & 15,68 & 515 \\
\hline
\end{tabular}


O Intervalo D é o que apresenta rochas com maior radioatividade. As médias de Th, $U, K$ e GR das rochas com acamamento heterolítico lenticular e dos argilitos deste intervalo chegam a ser $5 \%$ superiores àquelas calculadas para as mesmas litologias considerando todo o testemunho, já em relação ao Intervalo C, tais médias chegam a ser $13 \%$ superiores.

O Intervalo E apresenta um padrão em sino muito bem marcado (Figura 9). Apesar da pouca representatividade dos conglomerados e, consequentemente, do pequeno número de medições, é nesta litologia que se observa a maior média de urânio $(U)$, o que não é acompanhado pelos demais radioelementos (Th e $\mathrm{K}$ - Tabela 1), mas é suficiente para promover a inversão dos valores da derivada de GR, negativa na base do intervalo e positiva no topo. Os arenitos argilosos e os siltitos do Intervalo $E_{\text {, quando comparados }}$ com os dos demais intervalos, apresentam valores mais elevados de Th, U e K (Tabela 1).

No testemunho de sondagem do poço 2-TB-1-PR, as curvas Th/U e Th/K (Figura 9) apresentam, como os demais dados, grande concentração em torno da média. Valores anomalamente elevados são observados de forma pontual e representam variações importantes na mineralogia e nas condições paleoambientais, conforme destaca o diagrama Th/U versus Th/K (Figura 10). A grande concentração de valores de Th/K entre 3,5 e 12 indica a presença de rochas que composicionalmente apresentam mistura entre diferentes argilominerais (illita, caolinita e montmorilonita); já os valores de Th/U entre 2 e 7, sugerem deposição sob condições preferencialmente disóxicas, evidenciando uma grande homogeneidade ao longo de todo o testemunho de sondagem, independente dos intervalos litológicos ( $A, B, C, D$ e E) caracterizados acima.

Os maiores valores calculados $(\mathrm{Th} / \mathrm{K}>12$ e Th/U > 7 - Figuras 9 e 10) estão associados as rochas com maior proporção de areia, englobando arenitos, arenitos argilosos e rochas com acamamento heterolítico fláser e, também, algumas camadas de siltito. Nota-se que as razões $T h / K>12$, indicativas de maior umidade, ocorrem preferencialmente nas rochas com maior percentual de partículas tamanho areia presentes nos intervalos A, B e C, enquanto as razões Th/ > 7 são observadas com maior frequência nos arenitos e rochas com acamamento heterolítico do intervalo D.

Ao longo de todo o testemunho analisado, mesmo nas sucessões essencialmente argilosas, não foram observados valores de Th/U < 2 (Figuras 9 e 10), que sugerem deposição em ambiente essencialmente anóxico, em contextos marinhos profundos.

Apesar das tendências observadas e descritas acima, os valores de Th, $U$ e $K$ apresentam grande concentração em torno da média, o que se reflete em baixos valores de desvio padrão $(0,5<0<1,5)$ (Figura 11). A pequena dispersão dos dados e, consequentemente, a grande superposição de valores dificultam a identificação de padrões e impedem a construção de modelos confiáveis de predição litológica.

Para avaliar a autenticidade de tal afirmação, foram realizados testes estatísticos (Teste-t e ANOVA). A fim de satisfazer as condições de validade do Teste-t, as comparações foram realizadas utilizando apenas os dados percentuais do potássio $(K)$ e foram desconsideradas as litologias que, ao longo da sucessão de estudo, apresentaram um número de observações inferior a 95 (e.g. conglomerado e acamamento heterolítico fláser - Tabela 1). As 10 combinações possíveis com as cinco litologias restantes foram testadas e, com base nos valores-p obtidos (Tabela 2), o Teste-t sugere que somente o arenito, que apresenta P-valor $<10^{-3}$ em todas as comparações realizadas, possui diferença significativa em relação as demais litologias. Como o Teste-t está sendo aplicado com múltiplas categorias, ele perde sua precisão e pode resultar em falsos positivos, sendo importante calcular o poder do teste, ou seja, realizar uma avaliação que permite verificar se o teste é confiável nas condições dadas.

O poder do teste para a comparação realizada entre o arenito e o arenito argiloso, o arenito e o argilito e o arenito e rochas com acamamento heterolítico lenticular apresentou valores elevados, variando entre $95-85 \%$, o que sugere robustez e indica que, nestes três casos particulares, o Teste-t é confiável. 
O teste ANOVA realiza a análise da variância e, diferentemente do Teste-t, permite comparar simultaneamente todas as litologias descritas ao longo do testemunho do poço 2-TB-1-PR, independentemente do número de observações. O ANOVA retornou um valor- $F$ significativo $e$ um P-valor < 10-3 (Tabela 3) apontando que um dos itens analisados é diferente dos demais. Ao proceder o teste ANOVA sem considerar o arenito, litologia indicada pelo Teste-t como distinta das demais, o valor-F diminui e o P-valor aumenta
(Tabela 3), o que torna a significância do teste muito alta, sendo possível rejeitar a hipótese nula, ou seja, admite-se que todo o conjunto de dados analisado é similar.

Como o teste ANOVA apresentou um valor- $\mathrm{F}$ significativo, foram realizadas comparações múltiplas aplicando a Correção de Bonferroni, os P-valores obtidos (Tabela 4) confirmam que, com exceção do conglomerado, o arenito apresenta diferença significativa em relação às demais litologias.

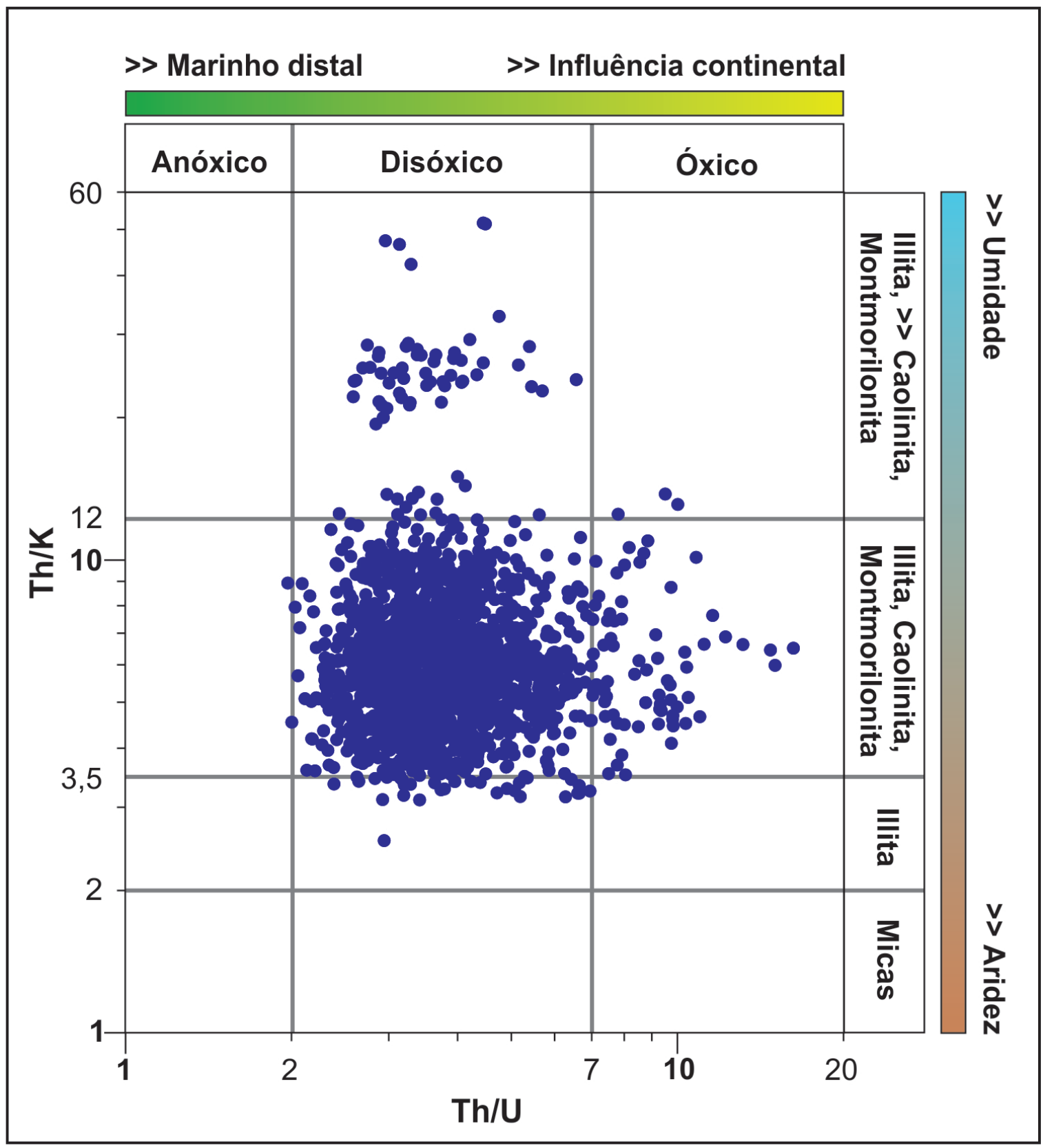

Figura 10. Razão Th/U versus razão Th/K ilustrando a distribuição dos valores calculados para o testemunho do poço 2-TB-1-PR e as inferências mineralógicas e paleoambientais que podem ser realizadas a partir dos dados (modificado de El Sharawy \& Nabawy, 2016).

Figure 10. Th/U ratio versus $T h / K$ ratio illustrating the distribution of calculated values for the drill core 2-TB-1-PR and the mineralogical and paleoenvironmental inferences that can be made from the data (modified from El Sharawy \& Nabawy, 2016). 


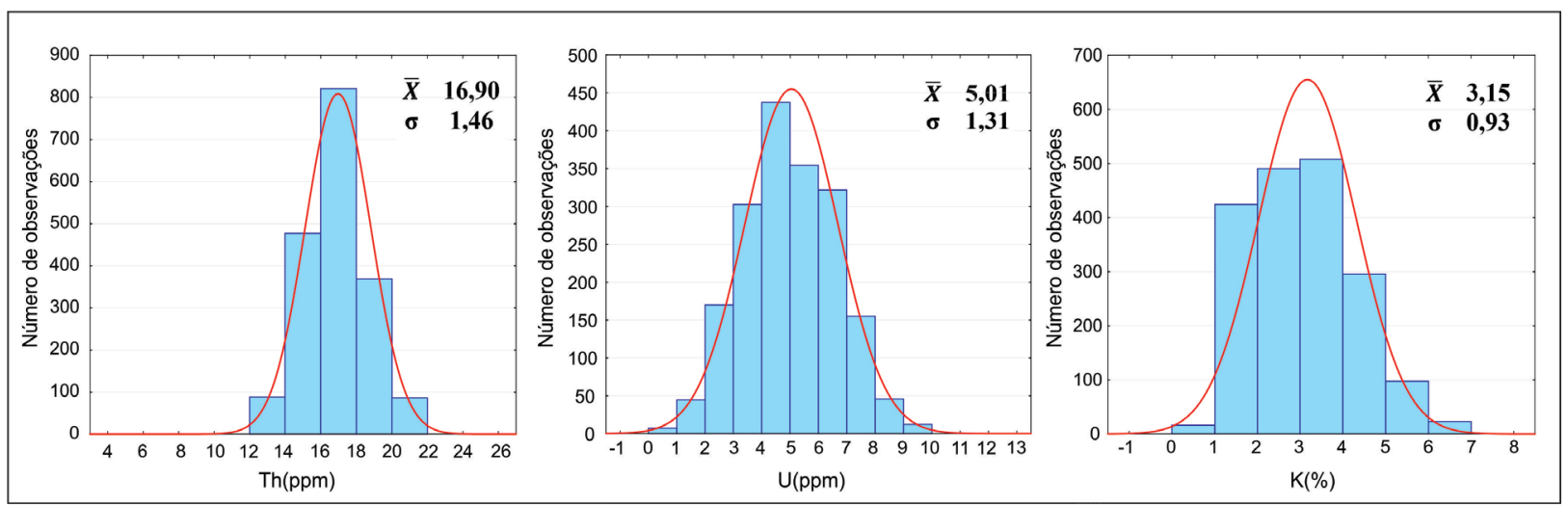

Figura 11. Histogramas com a dispersão dos valores de Th (ppm), U (ppm) e K (\%) medidos ao longo do testemunho do poço 2-TB-1-PR. Observa-se uma grande concentração de valores em torno da média aritmética $(\bar{X})$, o que se reflete em baixos valores de desvio padrão $(\sigma)$ e dificulta o estabelecimento de padrões.

Figure 11. Histograms with the dispersion of Th (ppm), $U(\mathrm{ppm})$ and $K(\%)$ values measured along the drill core 2-TB-1-PR. Note a large concentration of values around the arithmetic mean $(\bar{X})$, which is reflected in low values of standard deviation $(\sigma)$ and makes the establishment of standards difficult.

Tabela 2. P-valor obtido através do Teste-t considerando as combinações entre as cinco litologias descritas ao longo do testemunho do poço 2-TB-1-PR que satisfazem as condições de validade do modelo estatístico.

Table 2. P-value obtained through the t-Test considering the combinations between the five lithologies described along the drillcore 2-TB-1-PR that satisfy the vality conditions of the statistical model.

\begin{tabular}{ccccc}
\hline & $\begin{array}{c}\text { Arenito } \\
\text { argiloso }\end{array}$ & Argilito & $\begin{array}{c}\text { Acamamento } \\
\text { heterolítico } \\
\text { lenticular }\end{array}$ & Siltito \\
\hline Arenito & 0,0004 & 0,0001 & 0,0035 & 0,0314 \\
\hline Arenito argiloso & -- & 0,8699 & 0,5303 & 0,1906 \\
\hline Argilito & -- & -- & 0,4140 & 0,1298 \\
\hline $\begin{array}{c}\text { Acamamento } \\
\text { heterolítico } \\
\text { lenticular }\end{array}$ & -- & -- & -- & 0,4809 \\
\hline
\end{tabular}

Tabela 3. Síntese da análise de variância realizada através do teste de confiança ANOVA. Observe o valor-F e o $P$-valor nos dois casos analisados, o primeiro considerando todas as sete litologias descritas para o testemunho do poço 2-TB-1-PR e o segundo desconsiderando o arenito.

Table 3. Summary of variance analysis performed using the ANOVA confidence test. Observe the $F$-value and the $P$-value in the two cases analyzed, the first considering all seven lithologies described along the drill core 2-TB-1-PR and the second disregarding the sandstone.

\begin{tabular}{cccccc} 
& $\begin{array}{c}\text { Número de } \\
\text { variáveis }\end{array}$ & $\begin{array}{c}\text { Soma do } \\
\text { quadrado }\end{array}$ & $\begin{array}{c}\text { Quadrado } \\
\text { médio }\end{array}$ & Valor-F & P-valor \\
\hline Litologia & 7 & 1,929 & 0,386 & 21,315 & $2,2.10^{-16}$ \\
\hline Resíduo & 1.858 & 33,675 & 0,018 & -- & -- \\
\hline Litologia* & 6 & 0,277 & 0,069 & 3,848 & $4.1 .10^{-3}$ \\
\hline Resíduo* & 1.679 & 30,254 & 0,018 & -- & -- \\
\hline
\end{tabular}

* Teste ANOVA realizado sem considerar o arenito 
Tabela 4. P-valor obtido através de comparações múltiplas com Correção de Bonferroni considerando as combinações entre todas as sete litologias descritas ao longo do testemunho do poço 2-TB-1-PR.

Table 4. P-value obtained through the multiple comparisons with Bonferroni Correction considering the combinations between all the seven lithologies described along the drill core 2-TB-1-PR.

\begin{tabular}{|c|c|c|c|c|c|c|}
\hline & $\begin{array}{l}\text { Arenito } \\
\text { argiloso }\end{array}$ & Argilito & Conglomerado & $\begin{array}{c}\text { Acamamento } \\
\text { heterolítico } \\
\text { fláser }\end{array}$ & $\begin{array}{c}\text { Acamamento } \\
\text { heterolítico } \\
\text { lenticular }\end{array}$ & Siltito \\
\hline Arenito & $8.10^{-7}$ & $2.10^{-16}$ & 1,0 & $4.10^{-5}$ & $4.10^{-13}$ & $1.10^{-7}$ \\
\hline $\begin{array}{l}\text { Arenito } \\
\text { argiloso }\end{array}$ & -- & 1,0 & 1,0 & 1,0 & 1,0 & 1,0 \\
\hline Argilito & -- & -- & 1,0 & 1,0 & 0,108 & 0,017 \\
\hline Conglomerado & -- & -- & -- & 1,0 & 1,0 & 1,0 \\
\hline $\begin{array}{c}\text { Acamamento } \\
\text { heterolítico } \\
\text { fláser }\end{array}$ & -- & -- & -- & -- & 1,0 & 1,0 \\
\hline $\begin{array}{c}\text { Acamamento } \\
\text { heterolítico } \\
\text { lenticular }\end{array}$ & -- & -- & -- & -- & -- & 1,0 \\
\hline
\end{tabular}

\section{Discussão dos resultados}

\subsection{Correlação com as unidades litoestratigráficas que afloram no Arco de Ponta Grossa}

Com base na descrição do testemunho do poço 2-TB-1-PR pôde-se estabelecer a correlação entre os intervalos litológicos descritos (Quadro 1 e Figura 3) e as unidades litoestratigráficas propostas por Milani et al (2007) para a área de estudo.

O Intervalo A $(438,80-451,60 \mathrm{~m})$ é correlacionável a Formação Furnas, que segundo diversos autores (q.v. Bigarella et al.,1961; Borghi, 1993; Assine, 1999; Bergamaschi, 1999 e Lobato \& Borghi, 2005), é constituída por arenitos grossos a finos com estratificações cruzadas planares e/ou acanaladas com níveis conglomeráticos e intercalações de siltitos argilosos. O referido intervalo apresenta similaridades com o "intervalo intermediário" descrito por Assine (1999) devido, principalmente, a menor incidência e espessura de níveis conglomeráticos. Em relação a divisão proposta por Lobato \& Borghi (2005) para a sucessão da Formação Furnas que aflora entre os municípios de Castro e Tibagi (PR), o Intervalo A apresenta similaridades com o intervalo I, interpretado como parte de um sistema flúvio-deltaico entrelaçado de alta energia (braided deltas de McPherson et al., 1987).
O Intervalo B (432,60 - 438,80 m), cujos depósitos encontram-se dispostos de modo concordante sobre àqueles do Intervalo $\mathrm{A}$, pode ser correlacionado as "camadas de transição" de Petri (1948). As "camadas de transição" são interpretadas como o produto da transgressão que recobre os arenitos da Formação Furnas e culmina com a sedimentação dos folhelhos da Formação Ponta Grossa (Petri, 1948; Popp \& Barcellos-Popp, 1986; Assine et al., 1994).

A ausência do intervalo superior da Formação Furnas, conforme divisão proposta por Assine (1999), associada a relação de contato observada entre os intervalos A (intervalo intermediário da Formação Furnas) e B ("camadas de transição") indicam, localmente, uma paraconformidade (hiato deposicional).

O Intervalo C (208,10 - 432,60 m), que abrange uma seção sedimentar de mais de $220 \mathrm{~m}$ de espessura, é correlacionável ao descrito para o Membro Jaguariaíva, unidade basal da Formação Ponta Grossa. Tal unidade marca os estágios iniciais da transgressão responsável pelo afogamento dos sistemas parálicos do intervalo superior da Formação Furnas (Petri, 1948; Lange \& Petri, 1967; Assine, 1999; Bergamaschi, 1999; Milani et al., 2007). As laminações cruzadas por onda e estratificações cruzadas monticuladas (hummocky) identificadas pontualmente ao longo do Intervalo $\mathrm{C}$ reiteram que se trata do registro de um sistema marinho raso (plataformal) dominado por ondas e tempestades (Petri, 1948; 
Bergamaschi, 1999).

A partir do conteúdo de quitinozoários presente na seção-tipo do Membro Jaguariaíva Loboziak et al. (1995) estabeleceram que a unidade se estende desde o Praguiano até o Emsiano. Em estudos mais recentes Grahn et al. (2010) estabeleceram que a base do Membro Jaguariaíva apresenta idade de deposição entre o final do Praguiano e o início do Emsiano, intervalo de tempo compreendido no testemunho do poço 2-TB-1-PR (Neopraguiano ao Eo/ MesoGivetiano(?)).

O topo do intervalo C ( 208,10 - 232,50 m) é constituído essencialmente por rochas com acamamento heterolítico lenticular e siltitos intensamente bioturbados organizados em ciclos centimétricos a métricos de engrossamento granulométrico para o topo (coarsening upward) (Figura 3). Dada a espessura do Intervalo C, maior do que o esperado para o Membro Jaguariaíva, e o fato de o mesmo englobar rochas do Eifeliano, idade de deposição do Membro Tibagi (Lange, 1967 e Daemon et al., 1967), aventa-se a hipótese de o topo do referido intervalo representar fácies distais das progradações deltaicas descritas para o Membro Tibagi (Lange \& Petri, 1967; Assine, 1996; Milani et al., 2007).

O Intervalo D (13,00 - 208,10 m), com suas camadas mais frequentes e espessas de arenito, que ora se apresenta intensamente bioturbado ora exibe laminações cruzadas por onda e estratificações cruzadas monticuladas (hummocky) (Figura 3), écorrelato ao Membro São Domingos, unidade superior da Formação Ponta Grossa (Lange \& Petri, 1967; Milani et al., 2007), cuja idade de deposição abrange desde o Eogivetiano até o Neofrasniano (Oliveira, 1997). Esta unidade registra uma das mais importantes inundações da Bacia do Paraná e é interpretada como o registro de uma sedimentação em plataforma marinha, dominada pela ação de ondas (Bergamaschi, 1999), onde a chegada de material arenoso era constante e a remobilização de areias proximais em eventos de tempestade era intensa.

Pouco se discute na literatura acerca deste constante aporte de areia durante a deposição da Formação Ponta Grossa, que pode estar associado tanto ao soerguimento de áreas adjacentes, possivelmente associado a Orogenia Precordilheirana que se desenvolveu entre o Praguiano e o Emsiano no limite sul-ocidental do Gondwana (Milani \& Ramos, 1998; Sedorko et al., 2019), quanto por mudanças nas condições climáticas, favorecendo a formação de fluxos hiperpicnais (Mulder et al., 2003).

O topo da Formação Ponta Grossa é caracterizado pela discordância Neodevoniana (Milani et al., 2007), sendo o Membro São Domingos a unidade com o registro mais incompleto, algo observado no testemunho do poço 2-TB-1-PR pela ausência de parte dos depósitos do Givetiano e dos depósitos do Frasniano.

Por fim, o Intervalo E (0,00 - 13,00 m), que apesar de pouco espesso apresenta depósitos com cores amarelas / alaranjadas, únicos em todo o testemunho, é correlacionável aos depósitos basais do Grupo Itararé (Neocarbonífero - Eopermiano (Daemon \& Quadros, 1970; Souza, 2000)), que tem, comprovadamente, sua deposição influenciada pela glaciação permocarbonífera.

Dentre as diversas litologias reconhecidas para a referida unidade estão presentes no Intervalo E: (i) siltitos a siltitos arenosos mosqueados (Vesely, 2006 e Arab et al., 2009), formados a partir de fluxo gravitacional lamoso (Pickering et al., 1989) ou por decantação de plumas homopicnais oriundas do degelo (Vesely, 2006); (ii) arenitos argilosos maciços (Vesely, 2006 e Arab et al., 2009) associados a fluxos gravitacionais subaquosos de densidade (Talling et al., 2012); e (iii) conglomerados matriz sustentados maciços (Vesely, 2006 e Arab et al., 2009) cuja origem pode ser atribuída tanto a processos subaéreos, devido ao avanço de geleiras (Dreimanis \& Schlüchter, 1985), quanto a processos subaquosos, por deslizamentos e escorregamentos de massa (Martin, 1961).

\subsection{Considerações acerca dos dados de espectrometria de raios-gama}

Devido a pequena variação dos dados obtidos, modelos matemáticos indicam que, dentre as diversas litologias descritas ao longo 
do testemunho do poço 2-TB-1-PR, só é possível distinguir as camadas de arenito, estas tendem a apresentar valores mais baixos de K (\%) e GR (API) quando comparadas com todas as demais. Considerações e recomendações podem ser feitas levando em consideração as tendências das curvas, preferencialmente a de GR, e algumas anomalias observadas pontualmente. Além disso, as curvas e valores de Th/K e Th/U (Figuras 9 e 10) permitem realizar inferências relevantes sobre aspectos paleoambientais que vigoravam durante a deposição.

Os picos da curva de Th/K ocorrem ao longo de todo o testemunho, sempre associadas as camadas com maior proporção de areia e/ou silte. Os valores mais elevados de Th medidos e de $T h / K$ calculados são reconhecidos com maior frequência nos intervalos litológicos A, BeC(Figura 9) e, de acordo com Ruffell \& Worden (2000), indicam maior concentração de caulinita, além da presença de montmorilonita e illita (Figura 10). A maior contribuição de caolinita está intimamente associada a maior efetividade nos processos de transformação de feldspato, que, normalmente, está associada a episódios de sedimentação sob condições climáticas preferencialmente úmidas, ou, ainda, a percolação de fluidos bacinais com temperaturas entre $70^{\circ} \mathrm{C}$ e $100^{\circ} \mathrm{C}$, promovendo importantes modificações diagenéticas. Sob tais condições ocorre, devido à baixa solubilidade dos complexos de tório (Langmuir, 1978; Langmuir \& Herman, 1980), o enriquecimento relativo do radioelemento. O mesmo não ocorre para U e K, que são facilmente lixiviados.

A percolação de fluidos bacinais com temperaturas entre $70^{\circ} \mathrm{C}$ e $100^{\circ} \mathrm{C}$ são responsáveis não só pela transformação de feldspato e consequente enriquecimento em caolinita, mas também, pelos processos de transformação montmorilonita-illita (Pe-Piper \& Piper, 2019). Neste contexto, a realização de estudo mineralógico é importante para confırmar a presença de tais argilominerais e para estimar seus percentuais de ocorrência, facilitando a interpretação dos processos deposicionais e diagenéticos.

Com relação aos valores de Th e $U$, sabese que o percentual de urânio, quando autigênico, é diretamente proporcional ao percentual de matéria orgânica presente nos sedimentos, isto porque, ambos depositam-se e apresentam seu melhor grau de preservação em ambientes anóxicos e de baixa energia, onde predominam rochas com elevada argilosidade (Lüning \& Kolonic, 2003). Quando tal relação não é verdadeira, trata-se de urânio detrítico, que bem como o tório, está relacionado ao aporte de terrígeno de origem continental, mais especificamente, a presença de minerais pesados, como zircão e monazita (Svendsen \& Hartley, 2001).

A partir da curva Th/U observa-se que, além de não haver valores $<2$, dados, normalmente, pela abundância de urânio autigênico formado em condições de anoxia, em associação com folhelhos marinhos de zonas profundas, valores superiores a 7 são frequentes (Figura 9), indicando condições oxidantes (Figura 10) e deposição em sistemas marinhos rasos. Tais valores sugerem a ação constante de fluxos trativos, capazes de carrear sedimentos do continente para a plataforma e aumentar a oxigenação do meio, exercendo controle sobre a sedimentação e, também, sobre os organismos que se instalam no local e retrabalham o substrato. Com base nisto e na correlação positiva existente entre o U e o Th medidos, admite-se que ambos são de origem detrítica e não apresentam relação direta com o conteúdo de matéria orgânica, conforme argumenta Gama \& Pereira (2009).

Salienta-se que no intervalo compreendido entre 330 e $180 \mathrm{~m}$ de profundidade, englobando parte dos intervalos litológicos C e D (Figura 3), observa-se a menor recorrência de picos de Th/ $U>7$ (Figura 9), o que permite inferir que entre estas profundidades predominam as condições mais favoráveis para a preservação de matéria orgânica.

Tratando-se especificamente do padrão em sino observado nos intervalos litológicos basais A e B (Figura 9), fica claro que nem sempre um incremento nos valores de GR, acompanhado pelo aumento dos valores medidos dos três elementos radioativos, representa rochas argilosas. Além disso, os intervalos C e D apresentam diversas tendências dentro de uma mesma litologia, e quando há mais de uma litologia envolvida, nem sempre o maior GR 
representa a porção mais argilosa, o que pode ser claramente observado entre 90 e 70 m de profundidade (Figura 9).

As rochas do Intervalo $C$ tendem a apresentar valores de GR mais baixos do que àqueles do Intervalo $\mathrm{D}$, algo reiterado pela derivada de GR que mostra maior recorrência de tendências decrescentes em C. Tomando como referência os argilitos, admite-se que as diferentes tendências mencionadas acima ocorrem como reflexo das variações texturais. As sucessões essencialmente argilosas do Intervalo $C$, quando comparado ao $D$, tendem a apresentar maior proporção de grãos tamanho areia e silte dispersos na matriz, o que se reflete, diretamente, nos valores de raio-gama medidos. Nas demais litologias, tal variação pode ser reflexo tanto de mudanças texturais quanto composicionais, dentre as variações observadas, destaca-se a baixa proporção de micas, principalmente biotita, no Intervalo $C$, o que pode refletir uma mudança de área fonte entre os intervalos $\mathrm{C}$ e $\mathrm{D}$.

De acordo com as curvas de variação do nível do mar propostas para o Devoniano, desde o Neopraguiano até o Eo/MesoGivetiano(?), período de tempo abrangido nos intervalos B, C e D do testemunho do poço 2-TB-1-PR, há uma tendência de aumento do nível base, sendo os intervalos $\mathrm{B}$ e $\mathrm{C}$ relacionados as primeiras incursões marinhas do Devoniano ("camadas de transição" e Membro Jaguariaíva, respectivamente) e o Intervalo $D$ relacionado à deposição em condições de lâmina d'água marinha mais espessa (Membro São Domingos), o que se reflete diretamente nas médias crescentes de Th, U, K e GR observadas para as diferentes litologias dos três intervalos litológicos mencionados acima.

No Intervalo Ea maior média de U observada no conglomerado (Tabela 1), bem como os valores mais elevados de Th e $\mathrm{U}$ dos arenitos argilosos e dos siltitos podem ser associados com a baixa mobilidade destes elementos durante a atuação de processos pedogenéticos. Tais elementos podem estar associados a minerais resistatos, como a monazita e o zircão, e, quando liberados no sistema durante o intemperismo, tendem a ser rapidamente adsorvidos aos argilominerais e co-precipitados com oxi-hidróxidos de ferro, alumínio e manganês (Wilford et al., 1997). O potássio $(K)$, que também exibe valores superiores à média (Tabela 1), é depreendido dos minerais primários e adsorvido em argilominerais como a illita, a montmorilonita e, em menores proporções a caolinita. Tal radioelemento é geoquimicamente móvel e solúvel na maioria das condições de intemperismo, logo está presente apenas em perfis com pedogênese incipiente (Butt, 1987; Licht, 2001).

\section{Considerações finais}

Os cinco intervalos litológicos (A, B, C, $D$ e E) caracterizados no testemunho do poço 2-TB-1-PR apresentam correlação direta com as unidades litoestratigráficas descritas na região do Arco de Ponta Grossa. O testemunho apresenta um excelente controle estratigráfico, com arenitos atribuídos ao intervalo intermediário da Formação Furnas (Intervalo A) na base, seguidos, em paraconformidade, pelas "camadas de transição" (Intervalo B) e pela seção essencialmente lamosa da Formação Ponta Grossa (Intervalos C e D) e, no topo, em discordância, observa-se os depósitos do Grupo Itararé (Intervalo E).

A Formação Ponta Grossa, incluindo seus membros Jaguariaíva, Tibagi(?) (Intervalo C) e São Domingos (Intervalo D), corresponde a mais de $90 \%$ do material recuperado do poço 2-TB-1-PR e apresenta uma espessura superior a $420 \mathrm{~m}$, tratando-se de material inédito para a área de estudo. Apesar de ser uma seção mais espessa do que o estimado para a área de estudo ( 280 m), dados palinológicos indicam que tais rochas foram depositadas entre o Neopraguiano e o Eo/MesoGivetiano(?), salientando a ausência de parte do registro da sedimentação givetiana e da sedimentação frasniana.

As medições de radioelementos ( $T h, \mathrm{U}$ e K) e gama total (GR) realizadas ao longo de todo o intervalo recuperado apresentaram valores bastante similares, com pequena distribuição em relação à média. Testes estatísticos confirmam que, com exceção dos valores medidos diretamente no arenito, a população de dados não difere uma da outra, o que não permite a construção de um modelo estatístico 
confiável para predição litológica. Desta forma, a aplicabilidade de raio-gama espectral para distinção litológica em seções essencialmente argilosas pode ser questionada. A delimitação de camadas de arenito, principalmente as de maior espessura, são realizadas com facilidade, no entanto, a grande variedade de litotipos que podem estar contidos em uma sucessão argilosa não pode ser identificada.

Os padrões em sino e em funil observados e reiterados pela derivada de $\mathrm{GR}$, bem como as razões Th/Ke Th/U não são capazes de distinguir litologias, mas as singularidades identificadas podem ser atribuídas a variações nos aspectos composicionais e texturais de uma mesma litologia. Há sutis variações nas medições de radioelementos associadas a cada um dos cinco intervalos litológicos caracterizados, o que pode ressaltar variações intrínsecas ao paleoambiente deposicional e/ou modificações pós-deposicionais, como a atuação de processos pedogenéticos (e.g. Grupo Itararé) e a diagênese.

Agradecimentos. Os autores agradecem ao projeto da Universidade Federal do Rio do Janeiro (UFRJ), denominado "Projeto Folhelho - Caracterização geológica da qualidade de folhelhos marinhos do Devoniano da Bacia do Paraná do ponto de vista exploratório" (conv. Fundação Coppetec IGEO - 19301) financiado pela Geopark com recursos de Compromisso com Investimentos em Pesquisa e Desenvolvimento, sob supervisão da Agência Nacional do Petróleo, Gás Natural e Biocombustíveis - ANP P\&D. Agradecem também a Élvio Pinto Bosetti, do Departamento de Geociências da UEPG, e a Joana de Miranda Alencar pelo suporte nas etapas iniciais do estudo.

\section{Referências}

Adams, J.A.S. \& Weaver, C.E. 1958. Thorium to uranium ratios as indicators of sedimentary processes: example of concept of geochemical facies. AAPG Bulletin, 42: 387430.

Arab, P.B., Perinotto, J.A.J. \& Assine, M.L. 2009. Grupo Itararé (P-C da Bacia do Paraná) nas regiões de Limeira e Piracicaba - SP. contribuição ao estudo das litofácies. Geociências UNESP, 28(4): 501-521.

Assine, M.L., Soares, P.C. \& Milani, E.J. 1994. Sequências tectono-sedimentares mesopaleozóicas da Bacia do Paraná. Revista Brasileira de Geociências, 24: 77-89.

Assine, M. L. 1996. Aspectos da estratigrafia das sequências pré-carboníferas da Bacia do Paraná no Brasil. São Paulo, 207p. Tese de Doutorado, Programa de Pós-graduação em Geologia, Instituto de Geociências, Universidade de São Paulo.

Assine, M. L. 1999. Fácies, icnofósseis, paleocorrentes e sistemas deposicionais da Formação Furnas, no flanco sudeste da Bacia do Paraná. Revista Brasileira de Geociências, 29: 357370.

Bergamaschi, S. 1999. Análise estratigráfica do Siluro-Devoniano (formações Furnas e Ponta Grossa) da sub-Bacia de Apucarana, Bacia do Paraná, Brasil. São Paulo, 167p. Tese de Doutorado, Programa de Pós-graduação em Geologia, Instituto de Geociências, Universidade de São Paulo.

Bergamaschi, S. \& Pereira, E. 2001. Caracterização de sequências deposicionais de $3^{a}$ ordem para o Siluro-Devoniano na sub-Bacia de Apucarana, Bacia do Paraná, Brasil. In: Melo J.H.G. \& Terra, G.J.S. (Eds.) Correlação de Sequências Paleozoicas SulAmericanas: Seção Exploração de Petróleo. Ciência técnica petróleo, 20: 63-73.

Bigarella, J.J., Salamuni, R. \& Marques Filho, P.L. 1961. Considerações sobre a Formação Furnas. Boletim Paranaense de Geografia, 4-5: 53-70.

Borghi, L. 1993. Caracterização e análise faciológica da Formação Furnas (PrídoliDevoniano Inferior) em afloramentos do bordo leste da Bacia sedimentar do Paraná, Estado do Paraná, Brasil. Rio de Janeiro, 227p. Dissertação de Mestrado, Programa de Pósgraduação em Geologia, Instituto de Geociências, Universidade Federal do Rio de Janeiro.

Butt, C.R.M. 1987. A basis for geochemical exploration models for tropical terrains. Chemical Geology, 60(1-4): 5-16.

Cheeney, R.F. 1983. Statistical methods in 
geology for field and lab decisions. Londres, George Allen \& Unwin Ltd, 169p. ISBN: 0-04550029-0.

Daemon, R.F., Quadros, L.P. \& Silva, L.C. 1967. Devonian palynology and biostratigraphy of the Paraná Basin. Boletim Paranaense de Geociências, 21(22): 99-132.

Daemon, R.F. \& Quadros, L.P. 1970. Bioestratigrafia do Neopaleozóico da Bacia do Paraná. In: CONGRESSO BRASILEIRO DE GEOLOGIA, 24, 1970, Brasília. Anais... Brasília, SBG, v. 1, p. 359-412.

Dalgaard, P. 2008. Introductory Statistics with R. Second Edition, New York, Springer, 364p. ISBN: 978-0-387-79053-4.

Diez, D.M., Barr, C.D. \& Çetinkaya-Rundel, M. 2014. Introductory Statistics with randomization and simulation. First Edition, OpenIntro, 354p. Disponível em: < https://www.openintro.org/ download.php?file=isrs1_tablet $>$. Acesso em: 30 jul. 2019.

Dreimanis, A. \& Schlüchter, C. 1985. Field criteria for the recognition of till or tillite. Palaeogeography, Palaeoclimatology, Palaeoecology, 51: 7-14.

Droser, M.L. \& Bottjer, D.J. 1986. A semiquantitative field classification of ichnofabric. Journal of Sedimentary Petrology, 56(4): 558-559.

Droser, M.L., \& Bottjer, D.J. 1991. Ichnofabric and basin analysis. Palaios, 6: 199-205.

Fernandes, A.C.S. 1996. Os icnofósseis do Ordoviciano, Siluriano e Devoniano da Bacia do Paraná. Rio de Janeiro, 183p. Tese de Doutorado, Programa de Pós-graduação em Geologia, Instituto de Geociências, Universidade Federal do Rio de Janeiro.

El Sharawy, M.S. \& Nabawy, B.S. 2016. Geological and petrophysical characterization of the lower Senonian Matulla Formation in Southern and Central Gulf of Suez, Egypt. Arabian Journal for Science and Engineering, 41(1): 281-300.

Gama, R.M.A \& Pereira, E. 2009. Caracterização estratigráfica do intervalo Eodevoniano registrado na região de Jaguariaíva (PR), Bacia do Paraná, Brasil. In: CONGRESSO BRASILEIRO DE P\&D EM PETRÓLEO E GÁS, 5, 2009, Fortaleza. Anais... Fortaleza, ABGP, v. 1, p. 1-8.

Grahn, Y., Mauller, P.M., Breuer, P., Bosseti, E.P.,
Bergamaschi, S. \& Pereira, E. 2010. The Furnas / Ponta Grossa contact and the age of the lowermost Ponta Grossa Formation in the Apucarana sub-basin (Parana basin, Brazil): integrated palynological age determination. Revista Brasileira de Paleontologia, 13(2): 89102.

Grahn, Y., Mauller, P.M., Bergamaschi, S. \& Bosseti, E.P. 2013. Palynology and sequence stratigraphy of three Devonian rock units in the Apucarana Sub-basin (Paraná Basin, south Brazil): additional data and correlation. Review of Palaeobotany and Palynology, 198: 2744.

Koch, G.S. \& Link, R.F. 1970. Statistical Analysis of Geological data. Londres, Dover, 832p. ISBN: 0-486-64040-X.

Langmuir, D. 1978. Uranium solution-mineral equilibria at low temperatures with applications to sedimentary ore deposits. Geochimica et Cosmochimica Acta, 42: 547-569.

Langmuir, D. \& Herman, J.S. 1980. The mobility of thorium in natural waters at low temperatures. Geochimica et Cosmochimica Acta, 44: 17531766.

Lange, F.W. 1967. Biostratigraphic subdivision and correlation of the Devonian in the Paraná Basin. Boletim Paranaense de Geociências, 21/22: 63-98

Lange, F.W. \& Petri, S. 1967. The Devonian of the Paraná Basin. Boletim Paranaense de Geociências, 21/22: 5-55.

Licht, O.A.B. 2001. A geoquímica multielementar na gestão ambiental: identificação e caracterização de províncias geoquímicas naturais, alterações antrópicas da paisagem, áreas favoráveis à prospecção mineral e regiões de risco para a saúde no Estado do Paraná, Brasil. Curitiba, CD-ROM. Tese de Doutorado, Faculdade de Geologia, Universidade Federal do Paraná.

Lobato, G. \& Borghi, L. 2005. Análise estratigráfica da Formação Furnas (Devoniano Inferior) em afloramentos da borda leste da Bacia do Paraná. In: CONGRESSO BRASILEIRO DE P\&D EM PETRÓLEO E GÁS, 3, 2005, Salvador. Anais... Salvador, IBP, v. 1, p. 1-6.

Loboziak, S., Melo, J.H.G, Steemans, P. \& Barrilari, I.M.R. 1995. Miospore evidence for preEmsian and latest Famennian sedimentation in the 
Devonian from the Parana Basin, south Brazil. Anais da Academia Brasileira de Ciências, 67: 391-392.

Lüning, S. \& Kolonic, S. 2003. Uranium spectral gamma-ray response as a proxy for organic richness in black shales: applicability and limitations. Journal of Petroleum Geology, 26: 153-174.

Martin, H. 1961. The directions of flow of the Itararé ice sheets in the Paraná Basin, Brazil. Boletim Paranaense de Geografia, 10(15): 2577.

McPherson, J.C., Shanmugan, G. \& Moiola, R.J. 1987. Fan-deltas and braid deltas: varieties of coarse-grained deltas. Geological Society of America Bulletin, 99: 331-340.

Milani, E.J. \& Ramos, V.A. 1998. Orogenias paleozóicas no domínio sul-ocidental do Gondwana e os ciclos de subsidência da Bacia do Paraná. Revista Brasileira de Geociências, 28(4): 473-484.

Milani, E.J., Melo, J.H.G., Souza, P.A., Fernandes, L.A. \& França, A.B. 2007. Bacia do Paraná. In: E.J. Milani (Coord.). Cartas Estratigráficas Boletim de Geociências da Petrobras, 15(2): 265-287. Rio de Janeiro.

Mulder, T., Syvitski, J.P.M., Migeon, S., Faugères, J.C. \& Savoye, B. 2003. Marine hyperpycnal flows: initiation, behavior and related deposits: a review. Marine and Petroleum Geology, 20: 861-882.

Munsell Soil Color Book. 2012. Munsell Soil-Color Charts with genuine Munsell color chips. New York, The Geological Society of America, 15p.

Oliveira, S.F. 1997. Palinologia da sequência devoniana da Bacia do Paraná no Brasil, Paraguai e Uruguai: Implicações biocronoestratigráficas, paleoambientais e paleogeográficas. São Paulo, 188p. Tese de Doutorado, Programa de Pós-graduação em Geologia, Instituto de Geociências, Universidade de São Paulo.

Pe-Piper, G. \& Piper, D.J.W. 2019. Significance of the chemistry and morphology of diagenetic siderite in clastic rocks of the Mesozoic Scotian basin. Sedimentology, doi: 10.1111/ sed.12661.

Petri, S. 1948. Contribuição ao estudo do Devoniano paranaense. Boletim Técnico do
Departamento Nacional de Produção Mineral, DNPM -DGM, 129: 1-125.

Pickering, K.T., Hiscott, R.N. \& Hein, F.J. 1989. Deep Marine Environments: Clastic Sedimentation and Tectonics. London, Unwin Hyman, 416p.

Popp, J.H. \& Barcellos-Popp, M. 1986. Análise estratigráfica da sequência deposicional devoniana da Bacia do Paraná (Brasil). Revista Brasileira de Geociências, 16(2): 187194.

Quadros, L.P. \& Melo, J.H.G. 1987. Método prático de preparação palinológica em sedimentos do pré-Mesozoico. Boletim de Geociências da Petrobras, 2: 205-214.

Rider, M.H. 1990. Gamma-ray log shape used as a facies indicator: critical analysis of an oversimplified methodology. In: A. Hurst, M.A. Lovell \& A.C. Morton (Eds.). Geological applications of wireline logs - Geological Society of London Special Publication, 48: 2727.

Ruffell, A. \& Worden, R. 2000. Palaeoclimate analysis using spectral gamma-ray data from the Aptian (Cretaceous) of southern England and southern France. Palaeogeography, Palaeoclimatology, Palaeoecology, 155: 265283.

Sedorko, D., Guimarães Netto, R. \& Horodyski, R.S. 2019. Tracking Silurian-Devonian events and paleobathymetric curves by ichnologic and taphonomic analyzes in the southwestern Gondwana. Global and Planetary Change, 179: 43-56.

Silva, D.C. \& Vaine, M.E.E. 2001. Mineralogia do Paraná. Escala 1:650.000. Curitiba: Atlas Geológico do Paraná / Mineropar.

Souza, P.A. 2000. Palinobioestratigrafia do Subgrupo Itararé, Carbonífero / Permiano, na porção nordeste da Bacia do Paraná (SP / PR, Brasil). São Paulo, 199p. Tese de Doutorado, Programa de Pós-graduação em Geologia, Instituto de Geociências, Universidade de São Paulo.

Stephens, J.L. 1998. Theory and problems of beginning statistics. New York, McGrawHill, 413p. ISBN: 0-07-06-1259-5.

Svendsen, J.B. \& Hartley, N.R. 2001. Comparison between outcrop spectral gamma-ray logging and whole rock geochemistry: implications for quantitative reservoir characterization in 
continental sequences. Marine Petroleum Geology, 18: 657-670.

Talling, P.J., Masson, D.G., Sumner, E.J. \& Malgesini, G. 2012. Subaqueous sediment density flows: depositional processes and deposit types. Sedimentology, 59: 1937-2003.

Vesely, F.F. 2006. Dinâmica sedimentar e arquitetura estratigráfica do Grupo Itararé (Carbonífero-Permiano) no centro-leste da Bacia do Paraná. Curitiba, 226p. Tese de Doutorado, Programa de Pós-graduação em Geologia, Instituto de Geociências, Universidade Federal do Paraná

Zanotto, O.A. 1993. Erosão pós-Cretáceo na Bacia do Paraná, com base em dados de reflectância da vitrinita. In: SIMPÓSIO SULBRASILEIRO DE GEOLOGIA, 5, 1993, Curitiba. Anais... Curitiba, SBG, v. 1, p. 58-58.

Wilford, J.R., Bierwirth, P.N. \& Craig, M.A. 1997. Application of airborne gamma-ray spectrometry in soil/regolith mapping and applied geomorphology. AGSO Journal of Australian Geology \& Geophysics, 17(2): 201216. 